\title{
La "Justicia Social y Ecológica" y el Enfoque de los Bienes Fundamentales a la luz de una epistemología renovadora
}

Social and Ecological Justice" and the Perspective of Fundamental Goods in the light of a renewing epistemology.

A "Justiça Social e Ecológica" e a Abordagem dos Bens Fundamentais à luz de uma epistemologia renovadora

La "justice sociale et écologique" et l'approche des biens fondamentaux à la lumière d'une épistémologie en rénovation

从改造认识论看“社会生态正义”与基本商品的途径。

Eduardo R. Olivero $^{1}$ | Universidad Nacional de La Plata

Revista Derechos en Acción ISSN 2525-1678/ e-ISSN 2525-1686

Año 4/Nº 11 Otoño 2019 (21 marzo a 21 junio), 209-255

DOl: https://doi.org/10.24215/25251678e274

ORCID: https://orcid.org/0000-0002-0890-4675

Recibido: 20/03/2019

Aprobado: 17/05/2019

Resumen: Con sus luces y sombras, sus renovadas luchas y reivindicaciones y también sus crisis, debilidades, injusticias y exclusiones recurrentes (para una porción ciertamente mayoritaria de la población mundial), podemos ciertamente reconocer que mucho se ha discutido e implementado en poco más de medio siglo en términos de la institucionalización

\footnotetext{
1 Abogado (UBA, con diversos posgrados aprobados en UBA, UB y Univ. Austral). DocenteInvestigador (UNTDF, en las materias "Instituciones, Derecho y Economía" y "Teoría y Derecho Constitucional". Proyectos de investigación: en las áreas de energía y ambiente). Actualmente es funcionario del Poder Judicial de la Provincia de Tierra del Fuego A, e I A S. Autor y disertante en temáticas del derecho público.
} 
de garantías de acceso "a" y del goce (idealmente pleno e igualitario) "de" los derechos fundamentales (DF). No obstante, es innegable la crisis global actual de la democracia, la paz y de los propios DF, en el contexto del desarrollo in-sostenible pregonado por el capitalismo global y sus lógicas mercantilizadoras, maximizadoras y extractivistas reinantes. Ante estas dificultades, se ha propuesto que una de las expansiones necesarias del constitucionalismo global ha de ser el capítulo relativo a los bienes fundamentales. En este breve ensayo, intentaremos poner de resalto la comunión estratégica que cabe advertir entre los aportes de las epistemologías "del sur" - propias del pensamiento social que "tensiona" el desarrollo - y las mentadas ampliaciones constitucionales. Se plantean algunas bases para repensar una simbiosis crítica entre la Justicia social, la Ambiental y la Ecológica, postulando que el desarrollo de mayores instituciones de garantías (que "desmercantilicen" los derechos y bienes fundamentales, que creen las condiciones necesarias para su armónico desarrollo y que remuevan los obstáculos de sus actuales ataduras y fisuras) exige adoptar "normas de tareas" correlativas, dentro de una visión complementaria y estructural entre el "enfoque de derechos" y el "enfoque de los bienes fundamentales", reforzando en un todo la misión fundamental a cargo del Estado de garantizar la justicia social.

Palabras claves: Derechos fundamentales, Justicia social, bienes fundamentales.

Abstract: With its lights and shadows, its renewed struggles and demands and also its recurring crises, weaknesses, injustices and exclusions (for a majority of the world's population), we can recognize that much has been discussed and implemented in little more than half a century in terms of the institutionalization of guarantees of "access to" and the (ideally full and equal) enjoyment "of" fundamental rights (FD). Nevertheless, the current global crisis of democracy, peace and the DF itself is undeniable, in the context of the unsustainable development advocated by global capitalism and its prevailing mercantilizing, maximizing and extractivist logics. Faced with these difficulties, it has been proposed that one of the necessary expansions of global constitutionalism should be the chapter on fundamental goods. In this brief essay, we will try to highlight the strategic communion that can be noticed between the contributions of the "southern" epistemologies - characteristic of the social thought that "stresses" development - and the mentioned constitutional expansions. 
Some bases are proposed to rethink a critical symbiosis between Social, Environmental and Ecological Justice, postulating that the development of greater guarantee institutions (that taking market out of fundamental rights and goods, that create the necessary conditions for their harmonious development and that remove the obstacles of their current ties and fissures) demands to adopt correlative "task norms", within a complementary and structural vision between the "rights approach" and the "fundamental goods approach", reinforcing in a whole the fundamental mission in charge of the State to guarantee justice, reinforcing in a whole the fundamental mission in charge of the State to guarantee justice.

Keywords: Fundamental rights, Social justice, fundamental goods.

Resumo: Com suas luzes e sombras, suas renovadas lutas e reivindicações e também suas crises, fraquezas, injustiças e exclusões recorrentes (para uma parcela certamente maioritária da população mundial), podemos certamente reconhecer que muito tem sido discutido e implementado em pouco mais de meio século em termos da institucionalização de garantias de acesso "a" e do gozo (idealmente pleno e igualitário) "de" os direitos fundamentais (DF). No entanto, é inegável a atual crise global da democracia, da paz e dos próprios DF, no contexto do desenvolvimento insustentável pregado pelo capitalismo global e suas lógicas mercantilizadoras, maximizadora e extrativista reinante. Diante essas dificuldades, foi proposto que uma das expansões necessárias do constitucionalismo global deve ser o capítulo relativo aos bens fundamentais. Neste breve ensaio, tentaremos enfatizar a comunhão estratégica que deve-se notar entre as contribuições das epistemologias "do sul" - típicas do pensamento social que "tensiona" o desenvolvimento - e as mencionadas expansões constitucionais. Propõem-se algumas bases para repensar uma simbiose crítica entre a Justiça social, Ambiental e a Ecológica, postulando que o desenvolvimento de maiores instituições de garantias lque "desmercantilizem" os direitos e bens fundamentais, que criem as condições necessárias para seu harmonioso desenvolvimento e que eliminem os obstáculos de suas atuais ataduras e fissuras) exige adotar "normas de tarefa" correlatas, dentro de uma visão complementaria e estrutural entre a "abordagem dos direitos" e a "abordagem dos bens fundamentais", reforçando em um todo a missão fundamental carga do Estado de garantir a justiça social. 
Palavras-chave: Direitos fundamentais, justiça social, bens fundamentais.

Résumé: Avec ses lumières et ses ombres, ses luttes et ses revendications renouvelées ainsi que ses crises, ses faiblesses, ses injustices et ses exclusions récurrentes pour une partie certainement majoritaire de la population mondiale, nous pouvons certainement reconnaître que beaucoup de l'institutionnalisation des garanties d'accès "à" et de jouissance (idéalement complète et égalitaire) "des" droits fondamentaux. Cependant, la crise mondiale actuelle de la démocratie, de la paix et de ses propres droits fondamentaux est indéniable, dans le contexte d'un développement insoutenable proclamé par le capitalisme mondial et ses logiques commerciales, maximiseurs et extractivistes. Face à ces difficultés, il a été proposé que l'un des développements nécessaires du constitutionnalisme mondial soit le chapitre sur les biens fondamentaux. Dans cet essai, nous tenterons de mettre en évidence la communion stratégique entre les contributions des épistémologies "du Sud" - typiques de la pensée sociale qui "insiste sur le développement" - et les développements constitutionnels susmentionnés. Certaines bases sont proposées pour réfléchir à une symbiose critique entre la justice sociale, environnementale et écologique, postulant le développement d'institutions de garantie qui contribuent à décommercialiser les droits et biens fondamentaux , qui créent les conditions nécessaires à leur développement harmonique et suppriment les obstacles liés à leurs liens et fissures actuels. Cela nécessite l'adoption de normes de tâches corrélatives, dans le cadre d'une vision complémentaire et structurelle entre "approche des droits" et "approche des biens fondamentaux", renforçant ainsi dans l'ensemble la mission fondamentale de l'État de garantir la justice sociale.

Mot-clés: Droits fondamentaux, justice sociale, biens fondamentaux.

摘要: 当前的全球民主危机是不可否认的, 在全球资本主义及其商 业, 最大化和提取主义逻辑的推动下, 在可持续发展的背景下实现 和平。

面对这些困难, 有人提出全球宪政主义的必要扩展之一必须是关于 基本商品的章节。在这个简短的文章中, 我们尽量把突出的战略共 融应该认识论的贡献之间注意到 “南方” - 自己的社会认为“强调” 发 展 - 中提到的宪法和扩展。一些基地提出重新考虑社会公平, 环境和 生态之间的临界共生, 保证较高的机构 (发展基本权利和资产, 创造 
和谐发展的必要条件和扫除了障碍现有的债券和裂缝)需要通过 “标 准工作”相关, 在 “权利的办法”和 “基本商品的做法, ”加强整个任务 之间的互补性和结构性的愿景国家保障社会正义的基本责任。

关键字: 基本权利, 社会正义, 基本商品。

\section{Introducción: los derechos y bienes fundamentales ante la crisis global actual}

El desarrollo -asentado en renovadas epistemologías críticas y "desde el sur"- de determinadas "normas de tareas" estatales, reconociendo una simbiosis crítica entre la Justicia Social y la Ecológica y articulándose desde un "enfoque de los bienes vitales fundamentales" (en sustento de renovados fines y ampliaciones del Estado Constitucional), pueden en conjunto constituirse no solo en nuevos capítulos de las Constituciones (o de los instrumentos internacionales de garantía), sino en pilares de un refuerzo institucional idóneo y viable de los DDHH, de la democracia y de la paz, de cara a la innegable crisis global contemporánea que los afecta y oblitera, en una lógica destructiva sin precedentes.

Tales interrogantes, ponen la mirada en el desarrollo de las garantías de los derechos y de los bienes fundamentales que hacen a la dignidad y a la calidad de vida propia de un modelo de democracia sustancial e inclusiva. En ese marco, cabe interrogarnos por las bases epistemológicas y los enfoques y propuestas que nos brinden un "impacto" metodológico de utilidad, sea para el desarrollo del derecho (como saber) como de su praxis institucionalizada. La problemática advertida, en el contexto contemporáneo del capitalismo globalizado actual, implica no pocos desafíos epistémicos y políticos, visto que el desarrollo crítico, reflexivo e instrumental de tales propuestas queda fuertemente impactado y condicionado por la crisis de la democracia constitucional en curso.

Al decir de Ferrajoli -que compartimos plenamente- uno de los efectos implicados por esta crisis consiste en la disolución de las garantías de los derechos, sumado un progresivo 
desmantelamiento de la esfera pública y del Estado social -fomentado por las actuales políticas neoliberales- conculcando todo ello la principal fuente de legitimación del orden jurídico y político estatal e internacional.

En ese marco de análisis, las promesas de paz y de protección de los derechos fundamentales corren el riesgo de reducirse a su mera enunciación en el papel. Ante el fenómeno de la globalización económica, hay que advertir pues la presencia de un innegable vacío de derecho público en la materia, a la par del viraje regresivo hacia un neo-absolutismo ${ }^{2}$ de las grandes potencias y poderes trasnacionales.

Como lo expone sin rodeos Ferrajoli, en ausencia de una esfera pública mundial (donde no solo hay que ponderar el efecto de la guerra -revitalizada - sino de unos poderes económicos desregulados y salvajes ${ }^{3}$ ), el efecto más evidente de la globalización es el crecimiento constante de la desigualdad, signo de un nuevo racismo que considera inevitables a la

2 L. Ferrajoli, Democracia y derechos fundamentales frente al desafío de la globalización, "Lectio Doctoralis" en la oportunidad del doctorado honoris causa de la Universidad Nacional de La Plata, 22 de noviembre de 2005, https://www.uned.ac.cr/ecsh/images/ catDerPenal/TEMA1.pdf; recordemos que según nuestro autor en una democracia con una dimensión sustancial (constitucionalización de los derechos fundamentales) y a partir de sus límites y vínculos, se producen cambios en la naturaleza del derecho y de la democracia, debiendo tenerse presente al respecto que la esfera de aquello que ninguna mayoría puede decidir es aquella propia de la lesión de los derechos de libertad. Asimismo, la esfera de aquello que ninguna mayoría puede dejar de decidir, viene dada por la no satisfacción de los derechos sociales. El derecho internacional habría de ser "idóneo para regular los grandes poderes económicos transnacionales, que se sustraen así al rol normativo de los derechos públicos nacionales y se transforman en poderes desregulados y salvajes: un vacío de derecho público colmado, inevitablemente, por el derecho privado, es decir, por un derecho de formación contractual, producido por las empresas mismas, que se sustituyen de esta manera a las formas tradicionales de la ley...".

3 Insoslayables resultan aquí las referencias que deberíamos hacer a múltiples ensayos de N. Chomsky, relativos a la configuración del orden global, a la superviviencia humana, al miedo a la democracia, los mitos del mercado, los resultados regresivos de las políticas neoliberales, la manipulación y el rol de la opinión pública, las escaladas de violencia, la posibilidad actual de un desastre nuclear, la destrucción del ambiente y del planeta, etc.: ver por todos, Como funciona el mundo, Katz, Madrid, 2012; ¿Quien domina el mundo?, B.S.A., Barcelona, 2016; El beneficio es lo que cuenta. Neoliberalismo y el orden global, Austral. 
miseria, al hambre, a las enfermedades y a la muerte de millones de seres humanos considerados sin valor.

Una visión demasiado simplista podría apuntar a equiparar -sin más- la postulación en los textos de objetivos de cuidado y mejoramiento del medio-ambiente y de los bienes vitales, con el logro -presupuesto- de resultados inmediatos en la realidad, en términos de una mayor calidad de vida y de mejoras sociales acordes a cierta visión de la justicia social. La realidad, empero, funciona de modo en extremo más complejo, revelando la persistencia (in) sostenible de aquellos condicionantes, como de diversas crisis, tensiones y contradicciones vivenciadas en los límites de un proceso civilizatorio ${ }^{4}$.

Ciertamente requerimos, pues, de la mediación de la institucionalidad estatal y de las políticas públicas ${ }^{5}$, articuladas

4 0. Madoery, Los desarrollos latinoamericanos y sus controversias, UNTDF, Ushuaia, 2016, págs. 22, 281, quien destaca entre otros el objetivo de "tensionar el desarrollo", resaltando los planteos que disputan sus sentidos, en el marco de las contradicciones sociales y los proyectos políticos, presentando a su vez el debate sobre los fundamentos epistemológicos subyacentes.

5 En esta tesis también asumimos que el impacto de la "globalización" resulta mediado por la índole, "intensidad" y calidad de las políticas públicas asumidas. En una muy buena síntesis: " . . la retórica de la globalización distorsiona severamente los hechos al presentar lo que es una tendencia intrínseca y secular del modo de producción capitalista como si fuera un momentáneo e inesperado resultado. La manipulación ideológica a la que se presta el concepto de globalización es de tal naturaleza que conduce a las víctimas a creer que sus efectos y consecuencias son obra de ciegas fuerzas impersonales, la mera "secreción natural» de un orden económico global en donde no existen estructuras, clases, intereses económico-corporativos ni asimetrías de poder que cristalicen en relaciones de dependencia entre las naciones...De esta manera, a partir de un falso realismo se clausura la capacidad de pensar políticas alternativas y de "ver» las perniciosas consecuencias económicas, sociales y políticas de aquellas que se están implementando...Las mistificaciones no son entonces inocentes sino que contribuyen a desresponsabilizar a los gobiernos neoliberales y a las grandes megacorporaciones trasnacionales de las nefastas consecuencias de sus políticas. El aumento del desempleo, la caída de los salarios reales, la concentración del capital, el derrumbe de los sistemas de salud y educación pública, son atribuibles a una conveniente nebulosa denominada globalización...la noción de la desaparición de los Estados nacionales, o su incurable "impotencia» ante la fuerza arrolladora de la globalización, es un mito comparable a aquel que predica la evaporación de la geografía y el eclipse de los mercados nacionales... ante las tendencias supuestamente avasallantes de la "globalización" existe un considerable repertorio de respuestas nacionales que no necesariamente conduce al "dúmping social» o a las políticas antiobreras. Su impacto, 
desde el prisma de la simbiosis entre la "justicia social" y la "Justicia ecológica" en orden a visualizar y dar curso a renovadas "normas de tareas" e instituciones de garantías, las que idealmente -además- han de constituirse en nuevos capítulos del Constitucionalismo global, que evoluciona en sus etapas y estratos textuales.

Estas cuestiones se ven reflejadas hoy día en la problemática ambiental global y sus trasfondos económicos, políticos y socia$\operatorname{les}^{6}$, adquiriendo unos alcances contemporáneos -globales- sin precedentes, donde se van manifestando escenarios de desarrollo en controversia al tiempo que la explotación de los recursos naturales va de la mano con la profundización de la inequidad en cuanto al acceso a los bienes vitales fundamentales ${ }^{7}$.

Las implicancias para el contrato intergeneracional, para la justicia social y para el planeta mismo son no solo dolorosas, sino injustas, excluyentes y "suicidas" y nos conmueven -en el limitado punto que tocaremos aquí- a advertir la (urgente) relación de estos tópicos con el denominado "enfoque de los bienes vitales en acción" y a la vez con el enfoque de las "normas de tareas" del Estado, todo de conformidad a los fines -y sus herramientas- receptados por las actuales etapas evolutivas y textuales propias del Estado Constitucional ${ }^{8}$.

que es indiscutible, siempre se encuentra mediado por las políticas públicas, el desempeño gubernamental, la acción de los grandes conglomerados económicos y la fuerza de los partidos y sindicatos, en una palabra, el activismo y la capacidad de movilización de la sociedad civil...", A. Borón, "Pensamiento único y resignación política" (Revista Nueva Sociedad, nº 163, p. $140,146,147 / 148)$.

6 Orlando Rey Santos El Derecho Ambiental como garante de la justicia social, obrante en https://law.yale.edu/system/files/area/center/kamel/sela16_rey_cv_sp.pdf, estima que los vínculos entre estas cuestiones no suelen revelarse a primera vista.

7 L. Ferrajoli, Constitucionalismo más allá del Estado, Trotta, Madrid, 2018, p. 37 y ss y Principia luris. Teoría del Derecho y de la Democracia, Trotta, Madrid, 2011, Vol. I cap. 11.10 y Vol. II cap. 14.21 y cap. XVI.

8 Con sus correlativos procesos intensivos de crecimiento y diferenciación. Peter Häberle, El estado constitucional, UNAM, México, 2003, p. 247 y ss.: nos enseña que en los catálogos de tareas del Estado se encuentran temas típicos de los derechos fundamentales -entendidos 
En una idea y vuelta a partir de los planteos de ciertos autores influyentes (Häberle, Ferrajoli y otros), junto a la presentación de algunas renovadas bases epistemológicas del pensamiento social, iremos poniendo de resalto que los marcos institucionales -reforzados y revitalizados- deben ciertamente asumir aquella simbiosis crítica y la tesis acerca de la necesidad de expandir el paradigma constitucional a todos los poderes públicos y privados (y a las redes institucionales involucradas, también teniendo presente que el futuro del constitucionalismo implica una discusión que extiende sus fronteras más allá del Estado).

La propuesta en pie, entonces, importa discutir algunas bases y aspectos metodológicos de interés aparejados por aquellos enfoques, asentados en la simbiosis postulada entre la "Justicia Ambiental y Ecológica" y la "Justicia Social", con sus relevantes y renovadas epistemologías, que iremos apuntando.

En conjunto, arrojar luz sobre estos tópicos complejos e interrelacionados, habrá de prestar utilidad para "impulsar" la efectiva observancia de la obligación de respeto y garantía no solo de los derechos fundamentales sino también de los bienes vitales fundamentales (quebrando su mercantilización y combatiendo sus ataduras y fisuras), para lo cual juega un rol clave el planteo y desarrollo consecuente de un plexo de "normas de tareas" estatales, cuya misión sea actuar la justicia social en su contexto actual, como también buscando revitalizar a su respecto el estilo de vida democrático (formal y sustancial).

\section{Aportes para repensar la simbiosis "Justicia Social, Ambiental y Ecológica"}

¿Qué cabe decir hoy día del "desarrollo" y de la "calidad de vida" cuando advertimos fuertes contradicciones entre el

como límites y además como "tareas"- y en cuya tematización pueden darse no solo intersecciones sino, en lo que nos interesa aquí, conflictos entre objetivos (por ej. ecología y economía) (p. 249). 
capitalismo global, el ambiente, la ecología, lo social, etc..? Explicando este contexto, apuntamos aquí los siguientes puntos de interés para el debate, en orden a contribuir a repensar las bases -jurídicas- de una simbiosis crítica entre la Justicia Social, la Ambiental y la Ecológica":

II.1 El derecho, como todo saber y praxis institucionalizada, puede y debe -críticamente-evolucionar, teniendo presente nuevas bases y realidades, plenamente acordes a sus fines protectorios y garantistas. Lo mismo la sociedad, la cultura, la política, etc. que han de contribuir en ese marco -como de algún modo se ha ido manifestando con creciente interés- a forjar en conjunto una conciencia solidaria, equitativa y ecológica. Con renovados bríos, se trata de insertar en la matriz institucional vernácula nuevos vínculos y relaciones estratégicas, estructurales y complementarias entre los sujetos humanos y sus derechos y el ámbito de lo que podríamos denominar aquí como "no humano" (la naturaleza, otros seres vivos, la tierra, bienes, etc.). Este, como lo veremos a continuación, parece ser el "nudo gordiano", el quid de la cuestión jurídica contemporánea, también política, económica, social y cultural y de alcances globales.

Vínculos, relaciones y límites que -en términos del desarrollo de garantías idóneas y eficaces- también deben lograr traducirse, en definitiva, en un enfoque y lenguaje de derechos y en normas correlativas de "tareas estatales", si se trata de alcanzar a reducir la gran brecha entre el deber ser normativo y el ser efectivo de los sistemas políticos.

No podemos mantenernos -ni con ingenuidad ni con pasividad- ante la crisis actual del constitucionalismo democrático, con el riesgo de resultar desacreditado: "como un nuevo engaño y una nueva apariencia ideológica de Occidente... este fracaso del constitucionalismo democrático se debe a la ausencia, sobre todo en el derecho internacional, de garantías y, aun antes, de instituciones de garantía que estén 
a la altura de los nuevos problemas y de los nuevos poderes extra -o supra- nacionales".

Ello, nuevamente, nos coloca directamente en la problemática ambiental global ${ }^{10}$.

Eugenio Raúl Zaffaroni, con su agudeza habitual, expresa que la elaboración del derecho penal (lo que ciertamente podemos extender a otros ámbitos jurídicos) debe hacerse sobre bases realistas, sabiendo que el poder dominante considera a los sujetos carenciados como descartables, que como perspectiva tenebrosa se encuentra la de una necro-política genocida global y que, entre otros, el poder financiero se está liberando de la coerción política local y de la supranacional, al tiempo que impera en la región un tardo-colonialismo de sociedades excluyentes que destruye y debilita a los Estados, donde los medios monopólicos crean realidad.

La situación regional y global importa considerar que: “...dos tercios de la población del planeta carecen de lo necesario para vivir con dignidad... mientras un tercio consume mucho más de lo necesario, al tiempo que constantemente se le inventan nuevas necesidades suntuarias...De pretender elevar el nivel de consumo de los desfavorecidos hasta el del tercio beneficiado, se agotarian las condiciones ambientales que posibilitan la vida humana en el planeta... mientras el $1 \%$ de la humanidad

\footnotetext{
9 L. Ferrajoli, op. cit. como en nota $n^{0} 2$, punto 4.

10 Considerando que las previsiones científicas arrojan “...un diagnóstico unánime acerca del peligro que significa para la supervivencia de la especie humana el modo en que se relaciona el hombre con el medio ambiente...De lo que se trata entonces es que el modo en que por generaciones los hombres usaron el medio ambiente y el ritmo en que explotan, distribuyen y consumen los recursos naturales, se ha ido haciendo creciente y aceleradamente incompatible con la finitud del medio circundante, tanto para proporcionar los bienes necesarios para la continuación satisfactoria de la vida humana, como para recibir los desechos de la actividad de los hombres", Rey Santos, op. cit., p. 3/4, arribándose a un debate crítico por la reformulación -hoy día-, también con alcances globales, de las relaciones (productivas, de apropiación, consumo, conservación, uso, etc.) así establecidas con la naturaleza y el ambiente y además requiriendo la implementación de mejoras en términos de los derechos sociales y el acceso equitativo a tales recursos.
} 
constituye boy la nueva nobleza, pues concentra el 49\% de la riqueza, las amplias clases medias...se distribuyen el 14\%, con creciente tendencia a disminuir, lo que imputan a las molestias de los necesitados, cayendo en el racismo y la xenofobia..."11. En el mismo orden de ideas, Danilo Zolo ${ }^{12}$ ha expuesto
lúcidamente que el Derecho internacional está cada vez más

11 En Derecho Penal Humano, Hammurabi, Bs. As., 2017, p. 61/62. En otro texto, afirma: “... avanza por el mundo el poder de los Ceos de las corporaciones transnacionales con asiento en el hemisferio norte, que van ocupando el lugar de la política. Su innegable aspiración totalitaria se manifiesta en su cooptación de los aparatos estatales y económicos internacionales, racionalizada con su discurso único (mal Ilamado neoliberalismo), que domina a las academias mundiales y se vulgariza a través de los monopolios corporativos mediáticos. América Latina, como región subdesarrollada (colonizada en la nueva versión llamada globalización) es sometida a un proceso de acelerado debilitamiento de sus Estados mediante diversas y convergentes estrategias...el proyecto colonialista... pretende configurar una sociedad con mayoría excluida (... suele llamar sociedad 30 y 70), cuyo avance lo posibilitan básicamente dos condiciones que...no se hallas desvinculadas: (a) el consentimiento, resignación o apoyo de buena parte o de la mayoría de la población; y (b) los defectos de los Estados de la región, cuya institucionalidad no estaba preparada para defenderlos de la agresión... La primera condición resulta paradojal y hasta parece recursiva en la historia. Nuestra región ha pasado por momentos de marcada ampliación de la ciudadanía real en que gobiernos populares lograron elevar a condiciones dignas de vida a amplios sectores de la población...es necesario no dejar de lado los defectos de nuestros populismos, porque la paradoja del suicidio social de las capas beneficiadas por ellos, sin duda que debe responder a alguna de las fallas necesitadas de urgente corrección...cabe observar que el principal defecto ha sido precisamente el de dejar abierto el flanco de la segunda condición necesaria para la instalación de los proyectos colonialistas: los populismos no prepararon institucionalmente a nuestros Estados para resistir una agresión colonialista..." (en "iEstado Gendarme o Estado Fraterno?", publicado en REDEA, año 3, $n^{0} 7,2018$, p. 335/337 y 338/339).

12 En Los derechos humanos, la democracia y la paz en la era de la globalización, publicado en la revista electrónica Jura Gentium, VII (2011), 1 (disponible en http://www.juragentium.org/ topics/wlgo/it/braga.htm), rememorando la opinión de Luigi Ferrajoli cuando sostuviera: "El tiempo de los derechos es también el tiempo de su violación contundente y de la desigualdad más profunda e intolerable", en "Diritti fondamentali e democracia costituzionale", en P. Comanducci, R. Guastini (ed.), Analisi e diritto 2002-2003, Torino, Giappichelli, 2004, p. 347. El autor agrega una serie de cifras alarmantes y contundentes: "Bastan pocas cifras para confirmar dramáticamente el ocaso del 'tiempo de los derechos' en la era de la globalización. La Organización Internacional del Trabajo ha calculado que tres mil millones de personas viven hoy en día por debajo del nivel de pobreza, fijado en dos dólares de renta diaria. John Galbraith, en el prefacio del Human Development Report de Naciones Unidas de 1998, había documentado que el $20 \%$ de la población mundial más rica acaparaba el $86 \%$ de todos los bienes y servicios universalmente producidos, mientras que el $20 \%$ más pobre consumía solamente el 1,3\%. 
condicionado por los intereses políticos y económico-financieros de las grandes potencias, afectando el proceso de globalización el éxito y difusión de los derechos humanos fundamentales y la conservación y defensa de las instituciones democráticas (sustituidas por formas de ejercicio del poder concentradas y oligarquías elitistas, tecnocráticas y represivas), donde -entre otros- se observa que la violación de los derechos humanos es un fenómeno de proporciones crecientes, sin que los instrumentos, mecanismos y organismos creados a partir de la etapa de posguerra (ni por ende los propios principios afirmados en 1948 -por ej. en la D.U.D.H.-) hayan logrado eficacia y entidad protectoria suficiente. Zolo expone que la erosión de los derechos humanos, la democracia y la paz (caídos en el ocaso) es el resultado de un proceso global deseado por las potencias occidentales, además de estar garantizado por las instituciones económico-financieras que están comprometiendo las bases mismas de la existencia humana, la solidaridad y el proyecto de futuro.... aunque sin negar que valga la pena "luchar in extremis y desafiar el destino"13.

II.2 Contamos para tales desafíos con nuevas bases y epistemologías postuladas -que aquí presentaremos en sus lineamientos

Desafortunadamente, después de casi diez años, hoy estas cifras han cambiado: el 20\% de la población más rica consume el $90 \%$ de los bienes producidos, mientras que el 20\% más pobre consume el $1 \%$. Además, se ha calculado que el $40 \%$ de la riqueza del planeta la posee el $1 \%$ de la población mundial, mientras las 20 personas más ricas del mundo disponen de recursos equivalentes a los de las mil millones de personas más pobres. Además, de acuerdo a las cifras proporcionadas por las Naciones Unidas, mil millones de personas sobreviven en condiciones de 'pobreza absoluta' en los países económicamente más retrasados: alrededor de la mitad reside en Asia Meridional, un tercio en el África Subsahariana y una importante proporción en América Latina. En esta amplia franja de países, mil millones setecientas mil personas carecen de acceso al agua potable y se prevé que esta cifra se doblará en 2020. Cada año mueren más de dos millones de niños por falta de agua o a causa del agua insalubre, responsable del $80 \%$ de las enfermedades epidémicas. Además, la falta de agua es la causa de una drástica disminución de la producción alimentaria y de un aumento de las enfermedades vinculadas con la desnutrición. Entre las consecuencias del hambre y de la sed se suman los 25.000 niños que mueren cada día a causa de enfermedades que serían inocuas para niños bien alimentados...".

13 Con cita de N. Bobbio, II problema della guerra e le vie della pace, Bologna, il Mulino, 1984, pp. 94-5. 
centrales-, donde en referencia a la Declaración Universal de Derechos Humanos (y toda su lógica normativa e institucional ampliatoria y protectoria desarrollada globalmente desde 1948 -con sus luces y sombras-), podamos llegar a vincular otros saberes y praxis igualmente trascendentes -que no le quitan valor alguno- y en formación contemporánea (por ej. desde Ecuador, Bolivia y la postulación de una Declaración Universal de Derechos de la Naturaleza, o también de otros Seres Vivos -entre otros ${ }^{14}-$ ).

Al decir de trascendentes pensadores contemporáneos, existen ámbitos y temas donde es dable e imperioso repensar las epistemologías ${ }^{15}$ y donde la "ecología de saberes", la "traducción intercultural", los "mestizajes culturales, conceptuales y normativos", el uso "contra-hegemónico" de las instituciones, de la democracia y del derecho -entre otros-, se vuelven conceptos claves, en sus contextos apropiados, como aquél ajustado al "debate civilizatorio".

14 Ver A. Acosta, Hacia la declaración universal de los derechos de la naturaleza, AFESE 54, puede consultarse en el sitio https://therightsofnature.org. También recomiendo: Esperanza Martínez - Alberto Acosta, Los Derechos de la Naturaleza como puerta de entrada a otro mundo posible, Rev. Direito Práx., Río de Janeiro, Vol 8 n 4, 2017, p. 2927-2961 Tiempo atrás, el tema fue desarrollado con amplitud por Godofredo Stutzin, en Un imperativo ecológico: reconocer los derechos de la naturaleza, Amb. y Des. Vol. 1, p. 97-114, dic. 1984, puede consultarse en www.opsur.org.ar y también ver Julio M. Prieto Méndez, Derechos de la naturaleza. Fundamento, contenido y exigibilidad jurisdiccional, Corte Constitucional de Ecuador, CEDEC, Quito, 2013.

15 Boaventura de Sousa Santos, por ejemplo en su obra Refundación del Estado en América Latina Perspectivas desde una epistemología del Sur, IIDS, Lima, 2010: “ . . cuando es exitosa, la transición es en este caso también una transición conceptual, que se configura como mestizaje conceptual. Así, cuando la Constitución de Ecuador habla de los derechos de la Pachamama configura una mestizaje conceptual entre el mundo moderno de los derechos y el mundo andino de la Pachamama, a quienes nadie "puede dar derechos" una vez que ella sería la fuente misma de todos los deberes y de todos los derechos si tales conceptos perteneciesen a su cosmovisión. Asimismo, cuando las Constituciones de Ecuador y de Bolivia establecen el buen vivir (Sumak Kawsay o Suma Qamaña) como principio orientador de la organización económica, política y social, recurren a un dispositivo conceptual y normativo híbrido que junta en el texto jurídico matricial de la modernidad occidental —la Carta Política- recursos lingüísticos y conceptuales no coloniales y no occidentales..." (p. 65). 
Uno de los autores que aquí seguimos (Gudynas, más abajo citado) considera al efecto la necesidad de postular una ética biocéntrica, con nuevos puntos de discusión y opciones tales como: la reconfiguración de los sujetos políticos hacia posturas relacionales y no necesariamente dualistas; una política con mayor deliberación y participación; una inserción internacional volcada a un regionalismo autónomo; y una desvinculación selectiva de la globalización, entre otras.

Entre muchos autores, destacamos aquí a Leonardo Boff ${ }^{16}$, quien (además de hablarnos de "crisis de líderes", del "capital espiritual", de la "cultura del cansancio", de los "derechos del corazón", de una "ciencia para la vida" y de nuevos paradigmas fundados en el "acto de cuidar") pone de resalto los necesarios cambios en las concepciones del mundo que vienen aparejados al estar en juego una crisis civilizatoria sin precedentes,

16 “...Colocar la preocupación ecológica en el centro de la política supone enfrentar el mayor dilema de los gobiernos progresistas latinoamericanos: han puesto freno a los excesos del neoliberalismo, redistribuyen la riqueza, pero no están construyendo alternativas al modelo exportador de commodities (materias primas).La minería a cielo abierto, los monocultivos sojeros o la extracción de hidrocarburos avanzan en los países con gobiernos progresistas tanto como en los países con gobiernos neoliberales, y con las mismas consecuencias: devastación ambiental y destrucción de culturas y formas de vida de las comunidades rurales e indígenas. En Ecuador, Argentina o Bolivia, las políticas de redistribución de la renta, esas que han sacado a millones de personas de la pobreza en los últimos quince años, dependen de los ingresos de los emprendimientos extractivos. Y al mismo tiempo, en un proceso complejo y contradictorio, Ecuador y Bolivia han dado un paso de gigante al incluir en sus constituciones los derechos de la naturaleza, reconociendo así que... Ios elementos naturales tienen un valor intrínseco, más allá de la utilidad que obtienen los seres humanos de su explotación... Ecología: grito de la Tierra, grito de los pobres... La crisis actual, explica el teólogo, no es apenas económica, política o social; es una crisis civilizatoria donde lo que se quiebra es una concepción del mundo, esa según la cual 'todo debe girar alrededor de la idea de progreso', que se basa en la infinitud de los recursos de la tierra... La noción del Buen Vivir surge así como alternativa civilizatoria, como propuesta para recuperar el equilibrio entre los seres humanos y la naturaleza y sustituir el materialismo individualista por la satisfacción de necesidades legítimas -ya no deseos infinitos- para todos los seres humanos. 'Se trata de construir un nuevo tipo de ciudadanía socio-cósmica', señala Boff; y se trata también de recuperar la espiritualidad, lo sagrado, porque 'sin lo sagrado, la afirmación de la dignidad de la Tierra y del límite que habrá que imponer a nuestro deseo de explotación se quedará en una retórica ineficaz'..." (en www.ecoportal.net/ temas-especiales/desarrollo-sustentable/leonardo-boff-el-capitalismo-prefiere-ser-suicidaque-cambiar/). 
que se asentó en un modelo acumulativo y de explotación verdaderamente "suicida", siempre a costa de grandes mayorías explotadas y de injusticias sociales y ecológicas.

Al decir de Eduardo Gudynas ${ }^{17}$ : "la 'reforma' o la 'reparación' del capitalismo son posturas insuficientes. En algunos casos podrán ser necesarias para atender urgencias y problemas puntuales, pero no permiten cambiar, por ejemplo, las formas de apropiación de la naturaleza, la externalización y socialización de los impactos ambientales, o la inserción subordinada en la economía global... la salida a la crisis actual no es solamente una cuestión de cambios económicos, a pesar de la relevancia de esa temática, sino que debe ser más profunda, abarcando otras dimensiones, como la cultural y la politica...En ese camino es necesario abrirse a otras miradas éticas, en las cuales la naturaleza pasa a ser sujeto de derechos ${ }^{18}$, reconociéndosele valores propios. Es necesario abonar el camino para una transición desde el antropocentrismo al biocentrismo...".

En esa misma lógica, Alberto Acosta (en la obra citada en nota 18, pág. 317 y ss), nos habla del "derecho a la existencia"19,

17 En "La ecología política de la crisis global y los límites del capitalismo benévolo", en Revista de Ciencias Sociales. Num. 36, Quito, enero 2010, pp. 53-67.

18 Ver: Alberto Acosta y Esperanza Martínez (compiladores), La naturaleza con derechos: de la filosofía a la política, Ediciones Abya-Yala, Quito, 2011: “...cuando los límites de sustentabilidad del mundo están siendo literalmente superados, es indispensable buscar soluciones ambientales vistas como una asignatura universal. Por un lado, los países empobrecidos y estructuralmente excluidos deberán buscar opciones de vida digna y sustentable, que no representen la reedición caricaturizada del estilo de vida occidental. Mientras que, por otro lado, los países "desarrollados" tendrán que resolver los crecientes problemas de inequidad internacional que ellos han provocado. Al asumir su responsabilidad deben dar paso a una restauración global de los daños provocados y pagar sus deudas ecológicas con los países empobrecidos..." (p. 336). Para mayores datos y discusiones, me remito -además- a los diversos trabajos obrantes en el suplemento "personas no humanas" obrante en el sitio dpicuantico.com

19 Cabe tener presente la Constitución de Ecuador: "Art. 71.- La naturaleza o Pacha Mama, donde se reproduce y realiza la vida, tiene derecho a que se respete integralmente su existencia y el mantenimiento y regeneración de sus ciclos vitales, estructura, funciones y procesos evolutivos. Toda persona, comunidad, pueblo o nacionalidad podrá exigir a la autoridad pública el cumplimiento de los derechos de la naturaleza. Para aplicar e interpretar estos derechos se observaran los principios establecidos en la Constitución, en lo que proceda. El Estado 
manifestando que no hay razones para que -desde la ecologíalos sentimientos aparejados -la curiosidad, el amor- entren en conflicto con la comprensión científica de la naturaleza: pero las ideologías, la ciencia y la técnica no pueden separarnos de la naturaleza, ni conllevarnos a dominarla, explotarla y manipularla del modo en que tiene lugar hace tiempo dentro de la lógica brutal del capitalismo global -el foco se pone de modo absoluto en la maximización de resultados, la reducción de costos, la acumulación sin descanso de capital- también de tipo extractivista y mercanitilizadora respecto de la naturaleza; y todo conforme el particular papel que se pretende para nuestra región en la división internacional del trabajo.

Critica "Los limites de los estilos de vida sustentados en la visión ideológica del progreso antropocéntrico...cada vez más notables y preocupantes. Si queremos que la capacidad de absorción y resiliencia de la Tierra no colapse, debemos dejar

incentivará a las personas naturales y jurídicas, y a los colectivos, para que protejan la naturaleza, y promoverá el respeto a todos los elementos que forman un ecosistema. Art. 72.- La naturaleza tiene derecho a la restauración. Esta restauración será independiente de la obligación que tienen el Estado y las personas naturales o jurídicas de Indemnizar a los individuos y colectivos que dependan de los sistemas naturales afectados. En los casos de impacto ambiental grave o permanente, incluidos los ocasionados por la explotación de los recursos naturales no renovables, el Estado establecerá los mecanismos más eficaces para alcanzar la restauración, y adoptará las medidas adecuadas para eliminar o mitigar las consecuencias ambientales nocivas. Art. 73.- El Estado aplicará medidas de precaución y restricción para las actividades que puedan conducir a la extinción de especies, la destrucción de ecosistemas o la alteración permanente de los ciclos naturales. Se prohíbe la introducción de organismos y material orgánico e inorgánico que puedan alterar de manera definitiva el patrimonio genético nacional. Art. 74.- Las personas, comunidades, pueblos y nacionalidades tendrán derecho a beneficiarse del ambiente y de las riquezas naturales que les permitan el buen vivir. Los servicios ambientales no serán susceptibles de apropiación; su producción, prestación, uso y aprovechamiento serán regulados por el Estado".

Y la Constitución de Bolivia: "Artículo 33. Las personas tienen derecho a un medio ambiente saludable, protegido y equilibrado. El ejercicio de este derecho debe permitir a los individuos y colectividades de las presentes y futuras generaciones, además de otros seres vivos, desarrollarse de manera normal y permanente. Artículo 34. Cualquier persona, a título individual o en representación de una colectividad, está facultada para ejercitar las acciones legales en defensa del derecho al medio ambiente, sin perjuicio de la obligación de las instituciones públicas de actuar de oficio frente a los atentados contra el medio ambiente". 
de ver a los recursos naturales como una condición para el crecimiento económico o como simple objeto de las políticas de desarrollo. Y por cierto debemos aceptar que lo bumano se realiza en comunidad, con y en función de otros seres bumanos, como parte integrante de la Naturaleza, sin pretender dominarla”, agregando más adelante que: “...No se trata sólo de una deuda climática. La deuda ecológica, que se originó con la expoliación colonial -la extracción de recursos minerales o la tala masiva de los bosques naturales, por ejemplo-, se proyecta tanto en el 'intercambio ecológicamente desigual', como en la 'ocupación gratuita del espacio ambiental" de los países empobrecidos'..."

En esa misma lógica, Joan Martínez Alier ${ }^{21}$, teniendo presente que los problemas ecológicos son nuevos, complejos e interdisciplinarios (donde no caben metodologías y enfoques reduccionistas), nos plantea que existe un "comercio ecológicamente desigual” (“...El metabolismo de las sociedades ricas no

20 Ídem, p. 318 y 336, considerando que: “... Aquí cabe incorporar las presiones provocadas sobre el medio ambiente a través de las exportaciones de recursos naturales -normalmente mal pagadas y que tampoco asumen la pérdida de nutrientes y de la biodiversidad, para mencionar otro ejemplo- provenientes de los países subdesarrollados, exacerbadas por los crecientes requerimientos que se derivan del servicio de la deuda externa y de la propuesta aperturista a ultranza... Ios países más ricos han superado largamente sus equilibrios ambientales nacionales, al transferir directa o indirectamente "polución" (residuos, muchas veces tóxicos, o emisiones) a otras regiones sin asumir pago alguno..." (p. 336).

21 En "Conflictos ecológicos por extracción de recursos y por producción de residuos", que puede consultarse en la Revista "Letras Verdes. Revista Latinoamericana de Estudios Socioambientales", n 3, 2009, revistas.flacsoandes.edu.ec. Entre muchos otros autores de relevancia para el debate actual, conviene también tener presente los trabajos de E. Leff "La ecología política en américa latina: un campo en construcción", Polis, Revista de la Universidad Bolivariana, v. 2, n. 5, p. 125-145; "Aventuras de la Epistemología Ambiental: de la articulación de ciencias al diálogo de saberes", S. XXI; México, 2006, quien en "Imaginarios sociales y sustentabilidad. Cultura y representaciones sociales", año 5 núm. 9 UNAM, México, 2010, p. 42-121, poniendo de resalto la "alarma ecológica" y el "riesgo ecológico global" (la muerte entrópica del planeta), siendo éste el resultado de un modo de pensar y un modo de producir el mundo que han instituido globalmente un "mundo insustentable", destacando en definitiva el potencial neguentrópico del planeta para construir una sociedad humana fundada en una racionalidad productiva sustentable. 
se podría sostener sin conseguir a precios baratos los recursos naturales de los proveedores de materias primas. Es una condición estructural. Además, la capacidad de exigir pagos de la deuda externa ayuda a los países ricos a forzar a los pobres a la exportación de recursos naturales baratos...Los países que exportan materias primas deberían poner impuestos ecológicos a sus exportaciones, destinados a financiar una economía más sostenible..."), sumados los "pasivos ambientales de las empresas" ( "...Los balances y las cuentas de resultados de las compañias petroleras, mineras, madereras no incluyen los pasivos ambientales, esas deudas ecológicas. Los muchos intentos de iniciar juicios en Estados Unidos han tropezado con la negativa persistente en la forma de forum non conveniens..."), la "exportación de residuos tóxicos" ( “...LLa cuestión es, ¿por qué debemos decidir sobre asuntos de vida o muerte con criterios estrictamente económicos? ¿Quién ha dado ese poder a los economistas?...") y también la "deuda ecológica" (“...aumentan los conflictos ecológico-distributivos, es decir, no solo estamos perjudicando a las generaciones futuras de bumanos y eliminando otras especies que muchas veces ni siquiera conocemos, sino que hay también crecientes conflictos ambientales ya abora mismo...").

De estos autores, con sus fecundos y potentes aportes, podamos convenir -introductoriamente- en los siguientes puntos críticos de interés para el debate:

i) en el contexto de "mal-desarrollo" actual, prima un intercambio comercial y financieramente desigual;

ii) que también resulta en un intercambio ecológicamente desequilibrado, que genera notables desequilibrios y procesos lesivos en términos ambientales y sociales;

iii) En línea con Acosta -quien a la vez se remite a Ferrajoli- corresponde al respecto implementar mandatos y tareas relativas al objetivo de "desmercantilización", tal como se pregona en relación a los derechos humanos en general, en este caso también con respecto a la naturaleza; 
iv) En ese marco el "derecho a la existencia" es de los propios seres humanos, de la naturaleza, sus bienes y de todos los seres vivos, donde todos estos constructos mantienen una relación estructural, estratégica y complementaria.

En el caso de la naturaleza ello implica el mantenimiento de los sistemas de vida -los conjuntos de vida, los ecosistemas- mediante derechos que son representables y tutelados por personas y grupos.

Como lo sostiene Acosta, el seguimiento metodológico de un plano normativo y reconstructivo produce una reconceptualización profunda y transversal de los $\mathrm{DDHH}$, haciéndolo en términos ecológicos, pues al menos cabe reconocer que: "al final la destrucción de la Naturaleza niega las condiciones de existencia de la especie humana y por tanto atenta contra todos los Derechos Humanos... los Derechos Humanos y los Derechos de la Naturaleza siendo analiticamente diferenciables, se complementan y transforman en una suerte de derecho de la vida y a la vida" (ídem, pág. 355/356).

Compartimos también las conclusiones sostenidas por Martínez Allier sobre que los conflictos ambientales presentan distintos actores que tienen distintos intereses, valores, culturas, saberes, y también distintos grados de poder, que usan o pueden usar distintos lenguajes de valoración (por ej. puede ser que los poderes públicos y las empresas quieran imponer el lenguaje económico -análisis costo-beneficio, externalidades traducidas a dinero, evaluación de impacto ambiental; pero también caben otras miradas).

En un conflicto ambiental se despliegan valores ecológicos, culturales, de subsistencia de las poblaciones y también valores económicos. Son valores que se expresan en distintas escalas.

Coincidimos también con E. Leff, cuando sostiene que los imaginarios se convierten en bastiones de resistencia y medios de emancipación, en significantes estratégicos para legitimar otras formas de vida frente a la invasión de la globalización y ante los imperativos de la sustentabilidad. Poseen un potencial 
de creatividad y alteridad en la construcción de sociedades sustentables $^{22}$.

II.3 Superando el marco de la matriz colonial y eurocéntrica y una limitada mirada antropocéntrica, diremos que debemos entender que la dignidad humana y la calidad "de" y "en" la vida de las personas ( $\sin$ dejar de defenderla como se encuentra en sus estratos y etapas actuales - en amplio desarrollo convencional desde el contexto de posguerra-), va de la mano ${ }^{23}$ con otro proceso histórico de ampliación de derechos que hoy se encuentra cada vez más defendido, postulando su recepción como una nueva etapa textual del constitucionalismo: los derechos de la naturaleza y de otros seres vivos.

Las misiones y tareas estatales, fuertemente ligadas a la construcción histórica e institucional de los DDHH, también deben hacerse cargo de este recambio de paradigma en curso, donde los enfoques, tanto el de los "derechos fundamentales" como el de los "bienes fundamentales", junto a los mentados derechos

22 "...otro imaginario cultural —más arraigado en las cosmovisiones y tradiciones de los pueblos originarios andinos-, ha empezado a manifestarse en los foros de debate sobre la sustentabilidad. El imaginario del "vivir bien" se ha inscrito ya, después de la Cumbre de Cochabamba, en las agendas sobre el cambio climático como parte de las estrategias de los pueblos para ocupar su lugar en los debates y en la toma de decisiones que afectan sus condiciones de existencia. La discusión del "vivir bien" ocupó importantes espacios en la agenda y en las conclusiones de la Cumbre Mundial de los Pueblos ante el Cambio Climático y los Derechos de la Madre Tierra, celebrada en Bolivia en abril de 2010. Por su parte, la ética del "buen vivir" y los "derechos de la naturaleza" se han inscrito ya en la nueva Constitución de Ecuador como principios rectores de la planificación del Estado ecuatoriano..." (E. Leff, op.cit, como en nota 21 en último término).

23 Incluso puede recurrirse en términos -justamente- análogos a los de Germán J. Bidart Campos, en "Teoría General de los Derechos Humanos", Astrea, Bs As, 1991, p. 148 y respecto de los denominados "derechos por analogado". Ello, más allá de las estrategias internacionales, como sostiene Acosta, para poder potenciar los principios de vanguardia que tiene la Constitución ecuatoriana, como podría ser impulsar la Declaración Universal de los Derechos de la Naturaleza, así como el establecimiento de un tribunal internacional para sancionar los delitos ambientales. Para mayores desarrollos me remito a la ponencia de mi autoría expuesta en el libro colectivo titulado “Derechos Humanos: perspectiva y actualidad", Tres Tomos -Dir. Patricio Maraniello-, IJ Editores, Argentina, 2018, capítulo IV, artículo titulado "Sobre la construcción de la noción de sujetos de derecho no humanos". 
de la naturaleza y de otros seres vivos, han de ser puestos en visión armónica, estratégica, estructural y complementaria.

Sin desconocer ni afectar ni alterar los trascendentes reconocimientos de los derechos humanos, sus obligaciones correlativas y el desarrollo de las garantías pertinentes (dentro del denominado "enfoque de derechos"), conjunto que importa conceptuarlos como "inherentes a la persona humana" o a modo de "atributos de la persona humana", siempre en calidad de derivaciones directas de la dignidad de los seres humanos, entiendo que más allá de la discusión sobre si conviene o no hablar de "personas" o de "personalidad", cabe reconocer que existen razones de "peso" (ver trabajo citado en la nota 23) que desde las miradas y enfoques que venimos postulando y la síntesis enumerada en los párrafos previos, motivan la necesidad de equipararlos (por analogado) a aquellos sujetos titulares de derechos humanos, siendo dable abogar a tales fines por la calidad de "sujetos de derechos no humanos", representables por sujetos humanos.

Estas apreciaciones se asientan en el ámbito específico de discusión que venimos apuntando, considerando -así- en estos tiempos, que no obstante las crecientes advertencias científicas en la materia, las grandes conferencias generadas (desde Estocolmo -1972- a Río -1992- y muchas otras), los informes anticipados (el informe del Club de Roma -1972-) y la incorporación en la agenda pública de estas problemáticas, sumados los debates éticos y meta-éticos aparejados ${ }^{24}$, resulta que en el mencionado contexto del capitalismo global actual los avances concretos no son los idealmente esperados en términos de lograr acortar, prevenir y combatir las incompatibilidades y tensiones -de la que derivan injusticias sociales y ambientalesasociadas a los modos de producción, distribución y consumo prevalecientes.

24 Por todos, ver Dale Jamieson, Ethics and the Environment, Cambridge University, Press, New York, 2008. 
Aquél ámbito de discusión y éstos enfoques y herramientas planteadas como respuesta, se articulan frente a la comprobada e injusta realidad que nos indica que el carácter privado y los óptimos postulados para los procesos económicos -razón economicista y maximizadora- no coinciden con los óptimos sociales ni ambientales esperables ${ }^{25}$, como planteos y temas del bien común, de la cultura y de la simbiosis "justicia social y ecológica”. Es decir, como tema Constitucional.

Reconocer a partir de estos elementos de análisis, la necesidad de sostener una simbiosis crítica entre la Justicia social, la Ambiental y la Ecológica, nos permite en consecuencia postular que el desarrollo de mayores instituciones de garantías -que "desmercantilicen" los derechos y bienes fundamentales, que creen las condiciones necesarias para su armónico desarrollo y que remuevan los obstáculos de sus actuales ataduras y fisurasciertamente exige repensar:

i) las "normas de tareas estatales" que serían correlativas y derivadas de esta simbiosis y

i) articularlas desde una visión complementaria y estructural entre el "enfoque de derechos" y el "enfoque de los bienes fundamentales" (incluidos los "derechos de la naturaleza y otros seres vivos").

En suma, este es el camino postulado en orden a lograr reforzar la misión fundamental a cargo del Estado de garantizar la justicia social ante sus desafíos contemporáneos.

La "artificialidad social de la supervivencia" ${ }^{26}$, que apareja la necesidad de propender a la integración social, mediante la

25 “...El sistema ecológico actúa como proveedor de insumos al sistema económico, los que a su vez son utilizados para la producción de bienes o servicios. Al propio tiempo el sistema ecológico funciona como sumidero de desechos que son expulsados por el sistema económico como resultado de los procesos de producción y consumo. Bajo los patrones de desarrollo imperantes, el sistema económico no tiene en cuenta las exigencias del sistema ecológico...", Rey Santos, op. cit., p. 7.

26 Ver Ferrajoli, cit. como en nota 2. La garantía de los derechos sociales no sólo consiste en un deber impuesto por los instrumentos y convenciones constitucionales e internacionales, 
tutela de las condiciones materiales y las circunstancias jurídicas y sociales de vida que están y van más allá del ámbito de la libertad de iniciativa individual, ciertamente depende de aquella ya postulada mediación institucional y de las políticas públicas articuladas como técnicas de garantías. Yendo hacia una sólida construcción de esta mediación institucional y social, entiendo que es innegable considerar el aporte de la simbiosis planteada con la justicia ecológica, forjando la consecuente tutela de los derechos y de los bienes vitales fundamentales.

En ese trascendente tren de ideas, propiciando un modelo que sostenga una mayor intervención del Estado en el reparto y disfrute de los bienes yacentes creados en la economía, bajo la antedicha misión de la justicia social, el profesor Raúl G. Ferreyra $^{27}$ también discute la necesidad de sentar nuevas bases de certidumbre para la reforma de la institucionalidad -en crisis- de la Argentina, donde las mismas reglas constitucionales favorecen -según lo enseña- “...la sustanciación de modernos

\footnotetext{
sino que: "... antes bien, es una necesidad vital, debida al cambio profundo que se produjo en la relación entre hombre y naturaleza, que ha hecho de los derechos sociales a la supervivencia -a la subsistencia, a la alimentación básica, a la salud y a la educación- un corolario de aquel derecho a la vida que en el modelo hobbesiano del Estado moderno constituyó la primera razón de ser del contrato social de convivencia... En efecto, en las sociedades actuales, caracterizadas por un alto nivel de interdependencia y desarrollo tecnológico, incluso sobrevivir, no menos que vivir, requiere garantías jurídicas, puesto que también la supervivencia, no menos que la defensa de la vida ante agresiones indebidas, es cada vez menos un fenómeno solamente natural y cada vez más un fenómeno artificial y social... ".

27 R. G. Ferreyra, Sobre la paz y la justicia social, REDEA. DERECHOS en ACCIÓN | Año 2 № 3 | Otoño 2017: “... Los poderes hegemónicos extranjeros fuerzan a nuestros ciudadanos a un 'esclavismo social' que se define en gran escala, según la comprensión del Raúl Zaffaroni. La expansión, el agrandamiento del espacio de 'dominación colonial' del capitalismo trans o multinacional, coloca en cuenta regresiva la paz interna. Porque se trata de una agresión franca: la condena al subdesarrollo a nuestros ciudadanos bien intencionados...". El destacado autor también nos recuerda la opinión de Sampay en su discurso como miembro informante del Despacho de la Comisión Revisora de la Convención Nacional Constituyente de 1949: "Por justicia social, señor presidente, debe entenderse la justicia que ordena las relaciones recíprocas de los grupos sociales, los estamentos profesionales y las clases con las obligaciones individuales, moviendo a cada uno a dar a los otros la participación en el bienestar general a que tienen derecho en la medida en que contribuyen a su realización...".
} 
despotismos degenerados que impiden, lógicamente, la tutela de los intereses de todos...", operando un Mono-presidencialismo del que es esperable que "...desquicie y pulverice el fragmento constitucional referido a los derechos, bienes y deberes fundamentales". En ese marco, en dialogo con Sampay, rememora que la paz y la dicha del pueblo son los estadios más transcendentes, empero: "...la Argentina sufre una agresión que se concreta de diferentes modos, quizá en sus manifestaciones más evidentes: pago indebido a los "fondos buitres"; deuda externa contraída sin control ni límites; suma del poder público para la explotación sojera y minera; represión a sus ciudadanos (en especial, a la protesta social); aumento de tarifas de los servicios públicos; precarización del empleo de maestros y médicos, y otros trabajadores de la educación y de la salud; caída del empleo; freno a la obra pública; industria nacional a merced del Poder Ejecutivo Nacional; manejo antojadizo y extorsivo de los recursos del erario federal. El Estado constitucional, la mayor invención del hombre para la congregación de las coexistencias y la expectativa de una paz serena, se encuentra jaqueada. Colocada en entredicho, al menos la robustez de la paz social. El oficial público dispone políticas irracionales. Cualquier ciudadano en el auditorio podría preguntarse con legitimidad: ‘por qué?'. La Argentina se encuentra encadenada a los 'poderes salvajes supra-estatales', económicos y financieros, que originan que dos de cada tres argentinos sean desposeídos; ya sea pobre o población vulnerable a punto de serlo. Esa agresión provoca un severo proceso de desconstitucionalización del sistema político de la Argentina, que ya padece una inmunodeficiencia genética irrecuperable e irreversible: el monopresidencialismo..."28.

28 R. G. Ferreyra, Sobre la paz y la justicia social, REDEA. DERECHOS en ACCIÓN | Año 2 № 3 | Otoño 2017: “... Los poderes hegemónicos extranjeros fuerzan a nuestros ciudadanos a un 'esclavismo social' que se define en gran escala, según la comprensión del Raúl Zaffaroni. La expansión, el agrandamiento del espacio de 'dominación colonial' del capitalismo trans o multinacional, coloca en cuenta regresiva la paz interna. Porque se trata de una agresión franca: la condena al subdesarrollo a nuestros ciudadanos bien intencionados...". El destacado autor 
Es necesario, pues, para afianzar los objetivos trazados, que también logremos acometer el consecuente debate sobre la reforma de la institucionalidad pública en crisis, tratándose de un asunto sustancialmente ligado al éxito del debate y de las propuestas críticas generadas en torno a la problemática ambiental global y a las injusticias sociales acarreadas.

Concluimos este punto, reafirmando pues la simbiosis crítica postulada entre la Justicia social, la Ambiental y la Ecológica, que nos permitirá en consecuencia postular que el desarrollo de mayores instituciones de garantías -que "desmercantilicen" los derechos y bienes fundamentales, que creen las condiciones necesarias para su armónico desarrollo y que remuevan los obstáculos de sus actuales ataduras y fisuras- ciertamente nos exige repensar:

i) tanto las "normas de tareas estatales" que sean correlativas y derivadas de esta simbiosis y

ii) su articulación desde una visión complementaria y estructural entre el "enfoque de derechos" y el "enfoque de los bienes fundamentales" (incluidos los "derechos de la naturaleza y otros seres vivos").

Por este andarivel -como ya lo refleja el constitucionalismo andino-, corren las nuevas etapas del constitucionalismo contemporáneo, cuyos textos hemos de asentar aún más en las renovadas epistemologías comentadas, afianzando sus fines tuteladores, protectorios y garantistas respecto de los derechos y de los bienes fundamentales, como asimismo de la calidad de vida en democracia.

\footnotetext{
también nos recuerda la opinión de Sampay en su discurso como miembro informante del Despacho de la Comisión Revisora de la Convención Nacional Constituyente de 1949: "Por justicia social, señor presidente, debe entenderse la justicia que ordena las relaciones recíprocas de los grupos sociales, los estamentos profesionales y las clases con las obligaciones individuales, moviendo a cada uno a dar a los otros la participación en el bienestar general a que tienen derecho en la medida en que contribuyen a su realización...".
} 


\section{Bases para el desarrollo de "normas de tareas" desde un "enfoque de los bienes vitales fundamentales"}

Llegados a este punto en el debate, adoptamos las siguientes bases del pensamiento aplicado a los "derechos y bienes en acción", cuya lógica extendemos también al desarrollo y funcionamiento en conjunto de los conceptos entrecomillados en el sub-título.

III.1 Breve síntesis del "enfoque y la lógica de derechos humanos en acción" 29 y de la idea de "las normas de tareas estatales"

a) Este enfoque es el que habitualmente (luchas, acciones $\mathrm{y}$ reivindicaciones mediante) se pretende resulte receptado $\mathrm{y}$ aplicable a la praxis institucional -con crecientes y diversificados alcances, expansivos y ampliatorios- y normalmente ello traduce sus primeros efectos sobre el diseño y la orientación de las estructuras y los procedimientos estatales, en la institucionalidad pública, en las medidas públicas y en las formas de actuación del Estado en general. Así lo refleja la historia y la lucha por la

\footnotetext{
29 Ver: Sonia Solís Umaña, El enfoque de derechos: aspectos teóricos y conceptuales, www. ts.ucr.ac.cr. Para un enfoque de operacionalización de los derechos: Sandra Serrano - Daniel Vázquez, Los derechos humanos en acción: operacionalización de los estándares internacionales de los derechos humanos, Flacso, México. Al respecto me remito a las temáticas y autores analizados en E.R. Olivero, El interés público ante el "enfoque de derechos": análisis doctrinario y jurisprudencial, Jurisprudencia Argentina, Suplemento Derecho Administrativo (Coord.: C. Botassi), 2013-IV, fasc. 90 , del 27/11/ 2013. SJA 2013/11/27- 20 ; JA 2013-IV. ABELEDO PERROT No: AP/DOC/2813/2013 y El interés público y los derechos fundamentales, Revista Iberoamericana de Derecho Administrativo y Regulación Económica $\left(n^{0} 6\right)$, IJ Editores. Fecha de publicación: 17 de diciembre, 2013 (IJ-LXX-187), donde sostuvimos la propuesta que indica que la forma de eliminar la tensión que suele advertirse entre la eficacia administrativa (bajo la finalidad de persecución del interés general) y la defensa de los derechos de los particulares, es justamente vincular la mentada "concretización del interés público" con el referido "enfoque de derechos", lo que permite advertir dos cuestiones centrales para el análisis: 1) Que toda limitación de los derechos fundamentales debe tener lugar por ley; y 2) Que el Derecho Administrativo conecta al interés público (categoría constitucional) y a la gestión administrativa, con la garantía de la eficacia social de los derechos individuales y colectivos que encuadran su validez, legitimidad y consistencia en términos sustantivos constitucionales, con apertura a los ámbitos democráticos y pluralistas, a nuevas y complejas realidades, a los renovados y creativos tópicos de garantías, entre otros.
} 
ampliación de derechos y garantías articulada contra el poder estatal abusivo o requiriendo asimismo de sus roles y estrategias de intervención para lograr su tutela y satisfacción igualitaria.

Esta situación y cuadro normativo (político, cultural), hoy día, como ya lo vimos, debe extenderse y enfatizarse frente a los abusos y el absolutismo de los poderes privados.

Además, por las razones y bases que venimos comentando, también se torna necesario hacer una ampliación (textual, institucional) hacia el "enfoque de los bienes vitales fundamentales".

De aquél primer enfoque (el de los D.D.H.H.) normalmente se pretenden derivar los respectivos mecanismos (según los casos implicados) de "empoderamiento" de actores, como de vigilancia, de seguimiento y de monitoreo de los objetivos y resultados perseguidos. Todo ello se ha desarrollado, a su vez, conforme los respectivos marcos conceptuales ("robustos", pertinentes y apropiados), relativos a cada derecho fundamental en juego (ver por ej. las observaciones generales del Comité DESC -ONU- y de otros tantos comités intervinientes) ${ }^{30}$.

30 En un plano relacionado, hace tiempo que se vienen enfatizando determinadas consecuencias en materia de medidas, acciones y políticas públicas, traducidas en un lenguaje de exigibilidad y justiciabilidad de los derechos (Para un panorama general de este enfoque puede verse: Abramovich, V. su trabajo titulado "Los estándares interamericanos de derechos humanos como marco para la formulación y el control de las políticas sociales", en Abramovich, Victor- Alberto Bovino- Christian Courtis -compiladores-, La aplicación de los tratados sobre derechos humanos en el ámbito local. La experiencia de una década, Del Puerto, Bs As, 2007, Argentina; y respecto de los derechos sociales: ver Christian Courtis "Los derechos sociales como derechos", en Los derechos fundamentales, Editores del Puerto, Bs As., 2003). Cabe recordar aquí que del marco conceptual centrado en el cuerpo de principios, reglas y estándares del derecho internacional de los derechos humanos, se deriva -entre otras- la proposición de que tanto los derechos civiles y políticos, cuanto los derechos económicos, sociales y culturales, son indivisibles e interdependientes y constituyen un complejo de obligaciones negativas y positivas a cargo del Estado, con diversos pesos simbólicos en cada caso (a modo de un continuum de derechos). Así, las diferencias entre tales derechos son meramente de grado y no sustanciales, cobrando interés la visión que destaca la existencia de niveles de obligaciones estatales (por ej: obligaciones de respetar, proteger, garantizar, promover, etc.) que caracterizan al complejo que identifica a cada derecho en juego, independientemente de su adscripción como derecho civil, político o económico, social o cultural. Ver también de la Oficina del Alto Comisionado para los Derechos Humanos de las Naciones 
El rol desplegado por los órganos internacionales de aplicación y control de los DDHH (por ej. el caso de la Corte IDH), ha reforzado este enfoque -política, jurídica y culturalmente- $y$ la plena aplicabilidad y exigibilidad de los principios, reglas y estándares propios de una concepción jurídica de los Derechos Económicos Sociales y Culturales (DESC, art. 75 inc. $22 \mathrm{CN}$ ): desplegando para ello sentidos, tareas y obligaciones estatales vinculantes y forjando la adopción de mayores instituciones de garantía; lo que a su vez "potencia" la concordancia y la coherencia práctica entre la legalidad declarada, la institucionalidad y las prácticas socio-económicas y políticas imperantes ${ }^{31}$.

Esta visión adquiere valiosas connotaciones en términos sustantivos y procesales ${ }^{32}$.

Unidas, Los derechos humanos y la reducción de la pobreza. Un marco conceptual, 0NU, 2004, donde se establece un enfoque de derechos humanos aplicado a estrategias de reducción de la pobreza, con importantes derivaciones lógicas e innovaciones conceptuales. Uno de los puntos interesantes de análisis que se plantean, radica en la distinción entre diferentes formas en que los derechos humanos pueden ser pertinentes para la pobreza: pertinencia constitutiva, pertinencia instrumental y pertinencia restrictiva respecto del contenido y el ámbito de las estrategias de reducción de la pobreza (ver http://www.fao.org).

31 Al respecto es útil distinguir entre niveles de obligaciones estatales: i) la obligación de respetar (más propiamente vinculada a los limites negativos impuestos por los derechos al accionar del Estado o de terceros: no interferir con la libertad de acción y los planes de cada individuo o grupo en el modo de ejercicio de sus legítimos derechos, en el uso de sus recursos y medios propios o en la forma de autosatisfacción de sus necesidades económicas y sociales; no discriminar, etc.); ii) la obligación de proteger (prever estructuras y mecanismos de tutela de aquellas libertades y derechos frente a eventuales afectaciones causadas por terceros); iii) la obligación de garantizar (adoptar las medidas pertinentes para asegurar y satisfacer el acceso a y el goce efectivo del contenido mínimo exigible de cada derecho en juego: provisión de bienes o servicios básicos, tutela de sectores marginados o excluidos, etc.); y iv) la obligación de promover (discusiones sobre los medios y medidas de mayor alcance, formulación de políticas, programas, metas, modalidades y opciones de desarrollo progresivo, etc. favoreciendo aquí -mayormente- la acción de las instituciones democráticas). Las últimas tres obligaciones son más proclives a ser identificadas con obligaciones positivas, principalmente a cargo del Estado (sin mengua del control sobre las omisiones en adoptar medidas o realizar acciones).

32 En dicha línea, ver R. E. Gialdino, La protección de la vida y de la familia, y el derecho a la vivienda y a la seguridad social, en situaciones de pobreza extrema. Obligaciones positivas sustanciales y procesales del Estado, en JA Fasc. 4, 2008-IV, p. 3 y sigs. 
Como lo sostiene Abramovich, los estándares de derechos humanos sirven para fijar un marco para la definición de las políticas y estrategias de intervención tanto de los Estados como de los actores sociales y de las agencias de cooperación para el desarrollo, estableciendo una vara o criterio común para la fiscalización y evaluación posterior. En ello, cabe el entendimiento que los derechos humanos no son pensados tan sólo como un límite a la opresión y al autoritarismo, sino también como un programa normativo que guía, orienta y controla las políticas públicas de los Estados, contribuyendo al mismo tiempo al fortalecimiento de las instituciones democráticas.

Los marcos conceptuales acordes a cada derecho y a sus interrelaciones como derechos en acción, presentan un conjunto de exigencias, estándares, obligaciones y herramientas que son receptadas (gracias a la labor de los órganos de aplicación de los instrumentos internacionales) y desarrolladas por el lenguaje y la lógica del derecho de los derechos fundamentales y que resultan de insoslayable observancia crítica en y para la práctica institucional -con todas sus luces y sombras- ${ }^{33}$. Son basamentos

33 Existen diversos fenómenos críticos de nuestro específico medio regional y local, reconocidos en tempranas y valiosas obras politológicas. Por ejemplo, véase la obra de G. O'Donnell, en "Acerca del Estado, la Democratización y Algunos Problemas Conceptuales", en Desarrollo Económico. Revista de Ciencias Sociales, Nº 130, vol. 33, IDES, Bs. As.1993, donde se destaca el crecimiento en nuestro país de las "zonas marrones", fruto de la desintegración social y económica y de la crisis estatal, exponiendo que: “...en estas zonas hay elecciones, gobernadores y legisladores nacionales y provinciales (...). Aun cuando puedan ser los partidos de esas provincias miembros nominales de partidos nacionales, no son más que máquinas personalistas ansiosamente dependientes de las prebendas que puedan extraer de los organismos estatales, tanto nacionales como locales: Estos partidos y los gobiernos locales funcionan sobre la base de fenómenos tales como el personalismo, el facilismo, el prebendismo, el clientelismo (...). Estos circuitos de poder están representados en el centro de la política nacional (...) los intereses de los legisladores marrones son bastante limitados: sostener el sistema de dominación privatizada que los ha elegido y canalizar hacia ese sistema la mayor cantidad posible de recursos estatales (...) la tendencia de sus votos es conservadora y oportunista: dependen para su éxito del intercambio de favores con el Ejecutivo (...) estos políticos convergen con la orientación delegativa y cesarista del Poder Ejecutivo en su hostilidad a cualquier forma de responsabilización (accountability) horizontal (...) implica la introyección del autoritarismo(...) negación de lo público y de la efectiva legalidad del estado democrático y, por tanto, de la ciudadanía (...) un contexto autoritario tiene una característica 
necesarios para provocar avances políticos, culturales, jurídicos (en la comunión saber y praxis) en clave de garantías, delimitando ámbitos de intervención, límites, prohibiciones, vínculos negativos y positivos y todo un renovado plexo de relaciones con el mercado y con el Estado; tal como lo refleja el interesante y conocido desarrollo jurisprudencial y normativo internacional, nacional y subnacional producido en las últimas décadas y que hoy nuevamente se ve puesto en crisis a partir de los excesos y abusos propios del capitalismo global en curso -comentados en el capítulo anterior-

Este enfoque se dirige sobre todo a revertir problemáticas estructurales subsistentes y a combatir la precarización de las políticas públicas y sociales, mediante diversas estrategias de intervención (por ej. aquellas que buscan lograr el pasaje desde la negación o la asignación arbitraria y selectiva por el poder público de turno, al otorgamiento de derechos afirmados por un esquema institucional de garantías que se asienta con integralidad en el "enfoque de los derechos humanos": visualizando y tornando exigibles deberes, obligaciones y responsabilidades consecuentes según los casos involucrados ${ }^{34}$ ).

fundamental: no existe un sistema legal lo si existe no tiene verdadera efectividad, o puede anularse ad-hoc, o está subordinado a normas secretas o al capricho de los gobernantes) que garantice la efectividad de los derechos y garantías (...). En los países con grandes zonas marrones las democracias se basan en un estado esquizofrénico, en el que se mezclan funcional y territorialmente, importantes características democráticas y autoritarias. Se trata de un Estado cuyos componentes de legalidad democrática y, por lo tanto, de lo público y lo ciudadano se esfuman en las fronteras de diversas regiones y relaciones de clase, étnicas y sexuales (...). Un Estado incapaz de imponer su legalidad sustenta una democracia con una ciudadanía de baja intensidad (...). En muchas zonas marrones se respetan los derechos participativos y democráticos de la poliarquía, pero se viola el componente liberal de la democracia".

34 Como bien lo destaca Abramovich: "... el Estado ha subordinado a su propia discrecionalidad y al manejo clientelista las prestaciones o intervenciones que las Constituciones o pactos de derechos humanos proyectan como derechos (...) el reconocimiento de derechos en las Constituciones y en los tratados está destinado a imponer obligaciones a los poderes públicos" (Abramovich, op. cit., p. 247). Sobre los impactos producidos en materia de la discrecionalidad administrativa, me remito a E.R. Olivero La discrecionalidad administrativa ante los deberes funcionales de la Administración y las injerencias de los principios de derechos humanos, publicado en elDial.com, DC13E8, publicado el 12/08/2010. 
Vale recordar, asimismo, que los marcos conceptuales acordes al enfoque en comentario adquieren directa injerencia, principalmente, en la agenda pública estatal y también en torno a las estrategias de intervención jurídica en materia de políticas públicas y sociales. Para ello, como lo venimos enfatizando, el enfoque de derechos exige dotar a cada estrategia e intervención jurídica de un marco conceptual orientador explícito (bajo la presencia de estándares tales como la razonabilidad, la idoneidad/adecuación, la progresividad, la igualdad real de oportunidades, la garantía de los niveles mínimos y esenciales de disfrute de los derechos, etc...). Se pretende que dicho marco permita orientar y luego rendir cuentas - ante el dictado de políticas o medidas públicas- en torno a la relación entre el derecho humano de que se trate en cada caso, las obligaciones correlativas y las técnicas de garantía y exigibilidad que correspondan.

Por último, el "enfoque de derechos" concibe además a las personas como sujetos de su propio desarrollo -potenciando sus capacidades en la defensa de sus derechos-, más que como meras beneficiarias pasivas de las intervenciones estatales. Este enfoque, en fin, utiliza las normas sobre derechos humanos como un obligado marco referencial para el logro de ciertos objetivos (por ej. reducir la pobreza), aplicando y desarrollando valores y principios básicos de derechos humanos (no discriminación, universalidad, atención de grupos vulnerables, participación, indivisibilidad e interdependencia, roles de los titulares de derechos y obligaciones, empoderamiento, transparencia, rendición de cuentas, etc.) y sosteniendo sus injerencias -en clave de garantías- respecto de las tareas de elaboración, planificación, implementación, monitoreo, seguimiento, vigilancia, etc. de programas, planes y políticas públicas en general.

Para tales objetivos, cabe tener presente que el Estado puede adoptar al respecto diversas modalidades de regulación o de prestación de servicios, imponiendo incluso diversas restricciones, limitaciones u obligaciones a terceros (la exigencia de contar con recursos y previsiones presupuestarias no es la 
única forma posible de tutelar y satisfacer los derechos sociales -ni resulta ser la única medida exigible al Estado-).

b) En cuanto a la noción de "normas de tareas estatales", receptados por las actuales etapas evolutivas y textuales propias del Estado Constitucional ${ }^{35}$, debemos considerar que por un lado está el modelo "típico-ideal" inicial del constitucionalismo, el modelo de "facultamiento y delimitación" (parte orgánica y parte dogmática; razonamientos desde las "afectaciones y limitaciones"; énfasis en lo formal y lo técnico; ausencia de normas que definan funciones y tareas etc.-). Por el otro, viene estando cada vez más presente el "modelo de los valores fundamentales", tratándose de un tipo de constitución en cuyo texto -además de aquellos facultamientos y delimitaciones-, se expresan contenidos, valores, fundamentos y sobre todo "tareas".

En el marco comparado del Tipo del Estado Constitucional, cobran presencia pues las "normas de tareas", dando lugar a un campo "rico en la innovación y la fantasía, la diversidad de textos y la capacidad de diferenciación, incluso ambivalencia, de los constituyentes. Tales normas conquistan todas las partes y los campos problemáticos de la Constitución: desde el preámbulo, pasando por los derechos fundamentales, hasta la parte orgánica. Se dirigen a los destinatarios más variados (funciones del Estado, ámbitos de la sociedad o la economía) y van desde las cláusulas de 'preocupación'(...)artículos de 'protección' y 'promoción', hasta el mandato constitucional justiciable o el mandato legislativo(...)La creciente utilización

35 Con sus correlativos procesos intensivos de crecimiento y diferenciación. Peter Häberle, El estado constitucional, UNAM, México, 2003, p. 247 y ss.: nos enseña que en los catálogos de tareas del Estado se encuentran temas típicos de los derechos fundamentales -entendidos como límites y además como "tareas"- y en cuya tematización pueden darse no solo intersecciones sino, en lo que nos interesa aquí, conflictos entre objetivos (por ej. ecología y economía) (p. 249). Nuestro autor refiere que el homo economicus es una verdad parcial y que la sociedad abierta no es un "juego de ganancia económica", requiriendo ello un traslado de la estructura de la división de poderes hacia la economía. Dentro de los desafíos de la teoría constitucional (y también para la política constitucional) deben pues ser vinculados -en concordancia práctica- la ecología y la economía. 
de normas de tareas es una característica de la actual etapa evolutiva del Estado Constitucional y expresa una concepción diferente del Estado y de la Constitución (...) llama la atención la creciente intercambiabilidad entre los derechos fundamentales y las tareas del Estado (...) El estado no posee valor propio; sus tareas son, a final de cuentas, 'tareas de los derechos fundamentales" "36.

En este sentido y en el marco de nuestro estudio, podemos postular que el desarrollo de concretas "normas de tareas" en nuestros marcos institucionales debe verse articulado:

i) desde el interés de tutelar (instituciones de garantías) el acceso a y el pleno goce igualitario de los DDHH, respetando para ello las variadas exigencias metodológicas antedichas emanadas del "enfoque de derechos" (por ej. coherencia con los marcos conceptuales y con las obligaciones y responsabilidades derivadas según el derecho en juego; creación de condiciones y remoción de obstáculos; tutelando a la vez las mayores "intensidades" y garantías implicadas en la concreción de garantías vitales del contenido esencial e inalterable de los derechos ${ }^{37}$ );

36 Häberle, op. cit., p. 201 y ss.

37 Ver E.R. Olivero, El interés público ante el "enfoque de derechos"... cit. como en nota 29. La CSJN en autos: "Recurso de hecho 0. C. S. Y. v. Gobierno de la Ciudad de Buenos Aires s/amparo", del 24/4/2012, 0. 64 XLVI, sostuvo: "En el campo de las reglas normativas, ello significa que hay garantía mínima del derecho fundamental que constituye una frontera a la discrecionalidad de los poderes públicos", debiendo acreditarse en tal sentido: "una amenaza grave para la existencia misma de la persona", tratándose de "garantías mínimas indispensables para que una persona sea considerada como tal" (consid. $12^{\circ}$ ). En dicho fallo, se consideró que el "esfuerzo estatal realizado para garantizar los derechos (...) no es suficiente 0 adecuado" (consid. $13^{\circ}$ ), señalando que dicho esfuerzo debe ser "el resultado de un análisis integral para encontrar la solución más eficiente y de "bajo costo'” y debe ser "adecuado para garantizar la protección y al asistencia integral" del afectado (consid. 15\%). En referencia a los contenidos mínimos, en algunos fallos del alto tribunal se ha dicho que: "Todos los individuos tienen derechos fundamentales con un contenido mínimo para que puedan desplegar plenamente su valor eminente como agentes morales autónomos, que constituyen la base de la dignidad humana, y que la Corte Suprema debe proteger, y un principio de justicia que goza de amplio consenso es aquel que manda desarrollar las libertades y derechos individuales hasta el nivel más alto compatible con su igual distribución entre todos los sujetos que conviven en una sociedad dada, así como introducir desigualdades 
ii) atendiendo además -dentro de los objetivos de este ensayo- a los vínculos estratégicos y garantistas que venimos resaltando entre la justicia ambiental, la ecológica y la justicia social, conforme las renovadas epistemologías y perspectivas de abordaje previamente enunciadas y los aportes que sumamos en el punto III.2 siguiente.

Las "normas de tareas", importan el activo involucramiento -por todas las instancias estatales-, en cuanto a la concretización y objetivación en instituciones -sucesivas- de garantías de los contenidos de los derechos -y además de los principios, valores y bienes fundamentales-, todo desde la óptica de un relativamente nuevo lenguaje: aquel centrado en los "enfoques de derechos humanos" y, según lo entendemos, también en los enfoques de los "bienes vitales fundamentales", en sus justos ámbitos propios de tutela y sin menoscabar sus mutuas y estructurales relaciones.

III.2 Su concordancia con el "enfoque de los bienes vitales fundamentales": en tanto el paradigma del "acceso a los bienes básicos" es consistente y se refuerza mutuamente con el paradigma protectorio - tutela de los "débiles"- entre cuyas manifestaciones se encuentra el progresivo reconocimiento de derechos fundamentales ${ }^{38}$, metodológicamente articulado

excepcionales con la finalidad de maximizar la porción que corresponde al grupo de los menos favorecidos" (En autos: Itzcovich, Mabel c/ ANSeS s/ reajustes varios, sentencia del 29/03/2005. Fallos 328:566. Voto del Dr. Ricardo Luis Lorenzetti); “Quienes tienen a su cargo la administración de los asuntos del Estado deben cumplir con la Constitución garantizando un contenido mínimo a los derechos fundamentales (...) la Constitución no consiente interpretaciones que transformen a los derechos en meras declaraciones con un resultado trágico para los ciudadanos. Todos los individuos tienen derechos fundamentales con un contenido mínimo para que puedan desplegar plenamente su valor eminente como agentes morales autónomos, que constituyen la base de la dignidad humana, y que esta Corte debe proteger" (en autos: Ministerio de Salud c/Gobernación s/acción de amparo, sentencia del 31/10/2006. Fallos 329:4741).

38 G. Maurino, Derechos Sociales Fundamentales y bienes jurídicos protegidos en el Código. El caso de la Vivienda, http://ccycn.congreso.gob.ar/export/hcdn/comisiones/especiales/ cbunificacioncodigos/ponencias/buenosaires/pdfs/177_Gustavo_Maurino.pdf. En cuanto a 
desde el enfoque ya visto en el punto anterior, diremos que $a$ fortiori se advierte sin mayores complicaciones la plena complementariedad e interdependencia entre ambos enfoques postulados: el "enfoque de los derechos fundamentales" y el de "los bienes fundamentales" sustancialmente ligados al contenido de los derechos sociales y a la visión -ya enfatizada- de los D.E.S.C. en clave jurídica y de garantías (con mayor énfasis, reitero, en materia de tutela de los denominados mínimos vitales).

Demás está recordar aquí, como es bien sabido, que existen derechos "a" ciertos bienes fundamentales (sociales), que concretan estrechas e indisponibles relaciones a su respecto: por ej. el derecho al agua potable, así como el derecho al saneamiento, que son necesidades básicas y derechos fundamentales derivados del derecho a la salud ${ }^{39}$.

Siguiendo a nuestro autor de base (Ferrajoli: ver nota 7) en protección de los bienes vitales fundamentales, que son también universales y de accesibilidad garantizada para todos, éstos deben resultar sustraídos a la lógica del mercado vía la intervención del derecho (Ferrajoli divide a tales bienes en:

\footnotetext{
Ios derechos sociales, afirma:“.... su dimensión más robusta, aquélla de la cual genuinamente puede postularse una proyección emancipatoria o igualitaria, consiste en la garantía de acceso a ciertos bienes o servicios materiales fundamentales, o primarios, para la dignidad y autonomía -atención de la salud, alimentos, vivienda, agua, educación, un mínimo de disponibilidad de recursos económicos como resultado del trabajo o la protección social, etc.. Así como los derechos civiles fundamentales cumplen su función moral básica en su operación como inmunidades de una esfera personal de autodeterminación individual frente a intromisiones estatales o privadas, los derechos sociales encuentran su promesa más significativa en la garantía universal de acceso a las condiciones materiales primarias para que dicha autodeterminación sea significativa para cada ser humano...".

39 Urquhart Cademartori, Sergio y Mesquita Leutchuk de Cademartori, Daniela. (2014), “El agua como un derecho fundamental y el derecho al agua potable como un derecho humano fundamental: una propuesta teórica de políticas públicas". Jurídicas. No. 1, Vol. 11, pp. 117 137. Manizales: Universidad de Caldas, p. 128: "El derecho a la salud, por ser un derecho fundamental es universal, por lo que debe observarse la calidad del agua para consumo humano y la falta de saneamiento. El uso abusivo de ese recurso es una demanda del modelo de desarrollo económico ilimitado...".
} 
1.- personalísimos: órganos vitales del cuerpo ${ }^{40} ; 2$.- comunes: aire, ambiente, bienes ecológicos; 3.- sociales: el agua potable, alimentación básica, fármacos considerados esenciales). Ello requiere para su adecuada garantía adicionar una categoría diversa a la de los derechos fundamentales (precisamente la de los bienes fundamentales), cuyo lenguaje no alcanza ni resulta suficiente para asegurar per se tales objetivos y sus técnicas de tutela; aunque sean objeto de derechos sociales.

Ambos son indisponibles, pero nos enseña Ferrajoli que los derechos fundamentales tienen una indisponibilidad lógica e inviolable, son normas téticas (sus sujetos son siempre titulares de ellos hagan lo que hagan o quieran lo que quieran), mientras que los bienes fundamentales tienen una indisponibilidad jurídica y violable (en Principia Iuris, op. cit., Vol. 2, pág. 255/256) y solo pueden ser garantizados por la prohibición de disponer de ellos o por la obligación de hacerlos accesibles a todos (carácter deóntico: prohibición + prestación obligatoria).

Son amplios los espacios para el desarrollo de las mencionadas "normas de tareas" (protectorias, de gestión, de garantías, normas de defensa, etc.) en estos ámbitos: dirigidas al respecto, garantía y satisfacción de los DESC, al aseguramiento de niveles de vida adecuados, etc. (DUDH, PIDESC y cctes), en fin a dar andamiaje a la máxima de que hoy día "gobernar es igualar" (en términos del profesor Ferreyra). No sólo hay correspondencias entre los enfoques antedichos (de derechos y de bienes fundamentales) en cuanto a la necesidad -y los "empoderamientos" correlativos- de transparentar, debatir, combatir, controlar la existencia de situaciones o relaciones injustamente desiguales o discriminatorias, atentatorias de la existencia y subsistencia,

40 Donde se vehiculizan lógicas distorsionadoras y confusas entre el derecho real de propiedad-disponible- con los derechos fundamentales -indisponibles- tales como la salud y la integridad personal; Ver Ferrajoli, Principia luris, cit., Vol. 2, p. 258 y García Manrique, Ricardo, La propiedad sobre las partes separadas del cuerpo: un test para el enfoque propietarista, Revista de Bioética y Derecho, núm. 40, julio, 2017, pp. 49-61, Universitat de Barcelona, Barcelona, España. 
etc., sino que las medidas y políticas públicas perseguidas (cual eje de la necesaria mediación institucional advertida en el capítulo anterior) han de ser orientadas y fiscalizadas en función de (siempre siguiendo a nuestro encomiable autor de base):

i) la regulación (rígida y en términos de incompatibilidades) de los conflictos de intereses entre la lex mercatoria, la esfera pública y los derechos fundamentales, introduciendo mayores -y pertinentes- vínculos y límites para la tutela de los últimos y de los bienes fundamentales; quebrando la lógica seguida por el mal-desarrollo o el desarrollo insostenible actual, con sus efectos destructivos globales y en interés de viabilizar críticamente la simbiosis entre la "justicia social" y la "justicia ecológica" -desarrollada en el capítulo anterior-, enraizada en renovadas misiones y tareas estatales.

ii) la atribución a la esfera pública (función de "des-mercantilización") de todo lo relativo a la producción y distribución de bienes vitales fundamentales (bienes sociales: nuestro autor menciona al agua, alimentos básicos -política alimentaria y agrícola-, fármacos esenciales -patentamientos, ausencia de mercados, apartheid sanitario-; postulando la no privatización o patrimonialización, la prohibición de patentar, el aseguramiento de acceso, la garantía de mínimos vitales). Uno este punto con lo ya expuesto sobre la "artificialidad social" de la existencia y supervivencia -recuperando el derecho a la vida- y la creación de condiciones de vida y satisfacción de los DESC, en garantía de la supervivencia y la existencia y con la remoción de obstáculos -de toda índole-, también como misiones y tareas a cargo de los Estados a nivel local que ponen en juego la ya pregonada mediación de la institucionalidad pública y de las políticas públicas (intervención estatal social, inversiones sociales; todo más allá de las reformas a lograr en torno a las instituciones internacionales de garantías, conforme la creación de una esfera pública mundial y la fijación de una adecuada política económica y fiscal internacional - articulada desde las bases y epistemologías desde el sur desarrolladas en el capítulo anterior: contemplando entre otros la "deuda ecológica"-). 
iii) la limitación (también rigurosa) de la autonomía empresarial ante el carácter nocivo de ciertas actividades productivas o de los bienes producidos (impedimento de apropiación privada, destrucción, disipación, negociación de los bienes vitales comunes y sociales: aire, agua, integridad del ambiente, etc.; límites a la explotación ante el problema energético, desarrollo de energías renovables mediante intervenciones públicas, etc.).

iv) El desarrollo de suficientes e idóneas garantías primarias y secundarias (según cada órbita competencial y ámbitos de actuación) que aseguren la efectividad de las normas dictadas y las diversas responsabilidades en juego.

Surge patente la obligación de proveer universalmente (sobre todo hoy día, reitero, ante los poderes salvajes, fácticos y privados y ante todo abuso de poder o lo mismo de cara a la falta de prestaciones sociales oportunas, integrales y suficientes) adecuada asistencia, prevención, protección, promoción, etc. ante la efectivización de los DESC, tutelando asimismo y en plena concordancia a los "bienes vitales fundamentales" que son su objeto y sobre los cuales (a diferencia de los bienes patrimoniales) está prohibida su lesión y su disposición. Sabiendo que éstos pueden ser vistos como un derecho fundamental y como un "bien fundamental", es indudable que se insertan en la misma lógica de los derechos fundamentales, permaneciendo como tales indisponibles (universales, inalienables, inviolables) al Estado y al mercado ${ }^{41}$ (para Ferrajoli -a diferencia de los

\footnotetext{
41 Idem como en nota 39, autores que siguiendo a Ferrajoli, sostienen (p. 123) que la cuestión requiere "un análisis en el marco teórico del Estado de Derecho, estructura jurídico-política abocada a la tarea de proteger y garantizar valores, bienes e intereses considerados relevantes lo supremos) por la sociedad. La tarea de positivización de esas categorías comenzó con la proclamación de los derechos fundamentales, presentes en las constituciones de los Estados democráticos como reservas intocables para los poderes públicos, tanto públicos como privados. El próximo paso será entonces, a partir de la noción de derechos, deducir la categoría de bienes fundamentales, entendidos como merecedores de tutela igual a la de los derechos...". Asimismo, siguiendo al mismo autor, distinguen los bienes patrimoniales y los fundamentales: "Se Ilaman bienes patrimoniales aquellos bienes disponibles en el mercado a través de actos de disposición y de intercambio, a la par de los derechos patrimoniales de los que son el objeto, a cuyos titulares son reservados el derecho de uso y goce. Por otro lado, se denominan bienes fundamentales los bienes
} 
bienes personalísimos y los bienes comunes- al menos en la garantía de los contenidos mínimos vitales).

Los autores refieren allí que los bienes en sí mismos (vitales y por ello fundamentales) “...son valorados como objetos de garantía, incrementando los respectivos derechos fundamentales a través de la introducción de probibiciones de lesión o de obligaciones de prestación... el jurista italiano reivindica que a las innumerables cartas y convenciones, internacionales $y$ constitucionales de derechos fundamentales, deberian sumarse Cartas constitucionales y Cartas internacionales de bienes fundamentales, idóneas, por un lado, para garantizar los bienes personalísimos y los bienes comunes, con el fin de imponer límites rigurosos al mercado y al desarrollo industrial, y por otro lado como garantía de los bienes sociales, vinculándolos a la politica para volverlos accesibles a todos...".

En suma: proteger un bien como fundamental, como lo venimos exponiendo, importa atribuirle o reconocerle la calidad de "indisponible, inalienable e inviolable" y des-mercantilizarlo, sustrayéndolo del mercado y del arbitrio estatal o del legislador.

En este sentido, los bienes fundamentales -bajo tales presupuestos- complementan y se encuentran en interdependencia y relación estructural con el paradigma protectorio y garantista de los derechos fundamentales (que integran y refuerzan): las comentadas bases para el desarrollo de instituciones de garantías (con sus límites y vínculos impuestos) permiten su tutela efectiva, su protección y satisfacción en conjunto, sea ante los poderes privados o públicos, con matices diferenciadores.

Es realmente genial la referencia de nuestro autor de base sobre que los instrumentos de derechos fundamentales evocan y se relacionan con la idea del "contrato social" y que en el caso de la Carta internacional de bienes fundamentales ella se 
enmarca en una especie de "contrato natural" -convivencia con la naturaleza- ${ }^{42}$.

Se requieren pues instituciones públicas de garantía aplicadas también a los bienes comunes y a los bienes sociales, dentro del mismo enfoque protectorio y prestacional de los DDHH y con sus matices particulares según los casos. En una visión que excede (en el sentido de un plus) aquellos vínculos complementarios entre los enfoques considerados, este plexo de garantías no se limita a los derechos de los que son objeto tales bienes. Por lo contrario, se exige la previsión de "normas de tareas" -con el consecuente complejo de órganos y funciones administrativas- y a la vez "instituciones de garantía" de los bienes comunes y de los bienes sociales, garantizando su goce a todos en tanto objeto de derechos fundamentales.

Se trata del desarrollo de las instituciones de garantía primaria y secundaria de los bienes comunes (imponiendo límites estrictos y rigurosos a las actividades industriales y empresariales perjudiciales -salud, medio ambiente- y asegurando con eficacia las responsabilidades pertinentes -penales, civiles y administrativas-). También de garantías adecuadas para los bienes sociales -agua, alimentación básica, fármacos esenciales- con el fin distributivo implicado.

En suma, entre ambos enfoques está en juego, así, como factor "contra-hegemónico":

i) El incremento progresivo del grado de garantismo -también solidario- de un sistema jurídico;

ii) Al precisar y debatir los vínculos positivos o negativos impuestos a los poderes públicos -como también las zonas de

42 Michel Serres, en El Contrato Natural, Pretextos, Valencia, 1991, autor mencionado por Ferrajoli y que principia sus brillantes líneas sobre el contrato natural diciéndonos: “...nuestro conocimiento industrial interviene quizá de forma catastrófica en esa naturaleza global de la que los mismos antiguos pensaban que no dependía de nosotros..., en lo sucesivo, no sólo depende... sino que...nosotros dependemos, para nuestra vida, de ese sistema atmosférico cambiante..." -p. 49- 
discrecionalidad legítima posibles ${ }^{43}$ - y también a los poderes privados -y lo mismo en sus interrelaciones-.

Estos límites y vínculos, tranquilamente pueden desarrollarse del modo antedicho en un "enfoque de bienes fundamentales": donde varían aquellos vínculos y contenidos de los marcos conceptuales -pero no así el enfoque protectorio y garantista en juego-.

La cultura jurídica y política y su capacidad de análisis y de proyección (como respuesta frente a la injusticia y a la incertidumbre) nos permite insistir -en el marco ya comentado de recambios epistemológicos- en el valor expansivo y a la vez refundacional de la Constitución y de la "Teoría Constitucionalista", que hoy no solo hace, como lo vemos, a la interrelación de lo supranacional con lo constitucional, sino que se extiende a nuevas relaciones, "mestizajes" y etapas textuales.

El derecho y las instituciones formales deben coadyuvar a resolver -de modo integral- las tensiones reales presentes entre los campos sociales, económicos y ambientales, dirigiendo su accionar (preventivo, protectorio, garantista, solidario, etc.) hacia la tutela efectiva "de" y el acceso igualitario "a" los bienes vitales fundamentales, como método potenciador de las garantías de los derechos sociales.

Es innegable que hoy día debe expandirse el paradigma constitucional -como sistema lógico y formal de límites y vínculos- en todos sus niveles (internos e internacionales), en el desarrollo actualizado de garantías de los derechos sociales, frente a los ámbitos privados y también en garantía de los bienes vitales fundamentales; todo frente al absolutismo económico global reinante (primacía de la racionalidad económica cuantitativa, maximizadora y excluyente).

\footnotetext{
43 Sobre los impactos producidos en materia de la discrecionalidad administrativa, me remito a E.R. Olivero La discrecionalidad administrativa ante los deberes funcionales de la Administración y las injerencias de los principios de derechos humanos, publicado en elDial. com, DC13E8, publicado el 12/08/2010.
} 
Las injerencias -protectorias, garantistas, vinculantes- que así recaen obligadamente sobre el sistema legal e institucional y su praxis concreta consecuente, han de verse en plena concordancia y coherencia respecto de los recambios epistemológicos políticos y culturales apuntados en el punto anterior. El "enfoque de derechos" se traduce con la misma convicción -y potencialidad para la claridad metodológica- en un "enfoque de bienes fundamentales", que también despliega "normas de tareas" y configura instituciones de garantías.

En su mérito, las garantías han de extenderse a la tutela de los bienes vitales comunes, sociales, personalísimos y fundamentales $^{44}$.

Por último, el innegable costo de los derechos ${ }^{45}$, aplicado a los derechos sociales y a las condiciones de exigibilidad, pone de manifiesto lo indispensable de las inversiones públicas -evaluadas colectivamente y conforme la elaboración meditada de políticas públicas-, sin reflejar un "culto ciego" a las decisiones de mercado. Las contribuciones colectivas constituyen las libertades individuales y sociales: y ello adquiere relevancia sobre todo para obrar de modo protectorio frente a sus violaciones (por acción y omisión, agregamos). Solo un gobierno eficaz, reflejo de una sociedad políticamente organizada, transforma en plenamente exigibles las declaraciones formuladas en los textos fundamentales.

El bien común, el interés público, quedan pues revitalizados frente al economicismo excluyente reinante, debiendo los funcionarios $\mathrm{y}$ representantes -con transparencia $\mathrm{y}$

\footnotetext{
44 Hoy día ya no disponibles y accesibles a todos, sino patrimonializados y mercantilizados bajo la lógica absoluta del mercado. De tal forma se enfatiza y refuerza al mismo tiempo la garantía de los derechos sociales constituidos por aquellos bienes (por ej. afianzando así las posibilidades reales de cumplimiento de prestaciones obligatorias y universales, bajo los principios de indivisibilidad, interdependencia, de igualdad).

45 Ver S. Holmes - Cass R. Sunstein, El costo de los derechos. Por qué la libertad depende de Ios impuestos, Bs As, S. XXI, 2015, p. 225/239 y 245. Los autores afirman que no se puede definir quién es fuerte o débil en términos sociales sin saber de qué lado se encuentra la autoridad pública y sus decisiones sobre asignación de recursos escasos (p. 250).
} 
responsabilidad- explicar que principios e intereses ponderan cuando asignan beneficios, cargos y costos y sobre todo si estos últimos son parejos ante el contexto de poder reinante. En otros términos: ¿los protegidos son -cada vez más- ricos a expensas de quienes soportan las cargas de la protección?; ¿a quién benefician los limitados recursos, qué intereses maximizan, como pasan el test del bienestar general, el de la cooperación colectiva en términos de paz y calidad de vida, en términos de equidad y de justa distribución de la riqueza y de las oportunidades, etc.?.

En este sentido, es innegable, dicen los autores citados, que los derechos guardan relación con la democracia, la igualdad y la justicia distributiva y hay que discutir críticamente los costos de oportunidad de la utilización de los recursos finitos y escasos.

En este trágico, contradictorio, auto-destructivo, regresivo, injusto y excluyente contexto político, económico, social y ambiental global, se advierte como problema central -con claridad- que la estructura socio-económica y las matrices de apropiación, como también las actividades productivas, distributivas y de consumo imperantes, no aparejan una visión armónica de conjunto entre lo económico, lo social, lo ambiental ${ }^{46}$. Nuestra institucionalidad pública ${ }^{47}$ (como tampoco lo hace el derecho

46 Sobre los fundamentos, debates y acciones desplegadas en interés de lograr un tratado internacional vinculante para las corporaciones trasnacionales y la aplicación de mayores estándares en materia de gestión y tutela ambiental, de los DDHH y social, me remito a E.R. Olivero "Hacia un Pacto Internacional vinculante aplicable a los contenidos y alcances de la responsabilidad social corporativa: la gestión del impacto ambiental, social y de los derechos humanos" en el libro colectivo titulado "Pactos y Tratados Nacionales e Internacionales: Actualidad y Perspectiva" (P. Maraniello -Dir-, El Dial.com, Argentina, 2018), capítulo VII -sobre pactos nacionales e internacionales en el derecho ambiental-, p. 613/641.

47 Zaffaroni, "¿Estado Gendarme o Estado Fraterno?", publicado en REDEA, año 3, nº , 2018 : “... sólo esa solidaridad puede proporcionar fortaleza en la soberanía, porque ésta corresponde a los pueblos y, además, la fortaleza represiva suele ser propia de Estados débiles en soberanía. Toda copia imperfecta del viejo Estado de bienestar, carente de la simultánea concientización solidaria, no hará más que crear nuevas capas con subjetividades alienadas, que se suicidarán socialmente al identificarse y apoyar a sus enemigos, creyendo tener al alcance de la mano los privilegios de las minorías beneficiarias del totalitarismo corporativo colonialista... Los tres objetivos enunciados en el preámbulo de la Constitución de 1949 (soberanía política, independencia económica y justicia social) son interdependientes, pero su sustentabilidad en 
internacional, en términos de mayores instituciones de garantía) no parece asegurar tampoco una visión armónica entre estas dimensiones, con un énfasis tal que alcance a rediseñar, configurar y fortalecer una matriz estatal democráticamente revitalizada, equilibrada (entre los valores "igualdad, libertad, fraternidad") y con suficientes instituciones de garantía de derechos y de bienes fundamentales, sin perjuicio de resultar por demás imperiosa la articulación de una ciudadanía (más) solidaria.

De manera distinta a todas las otras catástrofes pasadas de la historia humana, la catástrofe ecológica es considerada por muchos pensadores y activistas como en parte irremediable, y ello nos coloca ante el factor del tiempo, con la imperiosa necesidad de concretar un aprendizaje colectivo preventivo, oportuno, correctivo y remedial. No podemos asumir el peligro de que se adquiera tardíamente la conciencia de la necesidad de estos cambios y de establecer un nuevo contrato natural.

A la par de los instrumentos de derechos fundamentales, pues, corresponde adoptar una Carta Constitucional de los Bienes Fundamentales, reconfigurando el rol de la esfera pública: incorporando prohibiciones, límites y vínculos adecuados, por un lado, a la producción y distribución de los bienes sociales y por el otro tendientes a la protección de los bienes comunes. Como lo sostiene Ferrajoli, tales límites han de ser rigurosos tanto frente al mercado como a la política.

\section{Conclusiones}

El contexto contemporáneo del capitalismo globalizado actual, implica no pocos desafíos epistémicos y políticos para el derecho y su praxis institucionalizada, sumada la nada inocua crisis de la democracia constitucional en curso. El carácter privado y los óptimos postulados para los procesos económicos -dentro de la lógica "neo-absolutista" de la razón economicista 
y maximizadora- no coinciden con los óptimos sociales ni ambientales esperables, como planteos y temas del bien común, de la cultura y de la simbiosis "justicia social y ecológica". Es decir, como tema Constitucional.

Demás está recordar aquí que la exclusión social y todas las nefastas consecuencias apuntadas en el ensayo derivadas de aquella lógica absolutista global imperante, atentan contra la indivisibilidad, interdependencia y universalidad de los derechos fundamentales y contra la democracia sustancial.

El desarrollo -asentado en renovadas epistemologías críticas y "desde el sur"- de determinadas "normas de tareas" estatales, reconociendo una simbiosis crítica entre la Justicia Social y la Ecológica y articulándose desde un "enfoque de los bienes vitales fundamentales" (en sustento de renovados fines y ampliaciones del Estado Constitucional), pueden en conjunto constituirse no solo en nuevos capítulos de las Constituciones (o de los instrumentos internacionales de garantía), sino en pilares de un refuerzo institucional idóneo y viable de los $\mathrm{DDHH}$, de la democracia y de la paz.

En este sentido, dijimos que el habitual "enfoque de derechos humanos" ha de articularse frente a los abusos y el absolutismo de los poderes privados y además se torna necesario hacer una ampliación (textual, institucional) hacia el "enfoque de los bienes vitales fundamentales".

El desarrollo de mayores instituciones de garantías -que "desmercantilicen" los derechos y bienes fundamentales, que creen las condiciones necesarias para su armónico desarrollo y que remuevan los obstáculos de sus actuales ataduras y fisuras- ciertamente exige repensar: i) las "normas de tareas estatales" que serían correlativas y derivadas de aquella simbiosis y ii) articularlas desde una visión complementaria y estructural entre el "enfoque de derechos" y el "enfoque de los bienes fundamentales" (incluidos los "derechos de la naturaleza y otros seres vivos").

Asumimos para ello la expansión del paradigma constitucionalista y la necesaria mediación de la institucionalidad estatal 
y de las políticas públicas, articuladas desde tales bases y propuestas, donde el desarrollo de concretas "normas de tareas" en nuestros marcos institucionales debe verse articulado: a) desde el interés de tutelar (instituciones de garantías) el acceso a y el pleno goce igualitario de los $\mathrm{DDHH}$, respetando para ello las variadas exigencias metodológicas emanadas del "enfoque de derechos" (por ej. coherencia con los marcos conceptuales y con las obligaciones y responsabilidades derivadas según el derecho en juego; creación de condiciones y remoción de obstáculos; tutelando a la vez las mayores "intensidades" y garantías implicadas en la concreción de garantías vitales del contenido esencial e inalterable de los derechos); y b) atendiendo además a los vínculos estratégicos y garantistas que venimos resaltando entre la justicia ambiental, la ecológica y la justicia social, conforme las renovadas epistemologías y perspectivas de abordaje previamente enunciadas.

Proteger un bien como fundamental importa atribuirle o reconocerle la calidad de "indisponible, inalienable e inviolable" y des-mercantilizarlo, sustrayéndolo del mercado y del arbitrio estatal o del legislador. En este sentido, los bienes fundamentales -bajo tales presupuestos- complementan y se encuentran en interdependencia y relación estructural con el paradigma protectorio y garantista de los derechos fundamentales (que integran y refuerzan): las bases para el desarrollo de instituciones de garantías (con sus límites y vínculos rigurosos impuestos) permiten su tutela efectiva, su protección y satisfacción en conjunto, sea ante los poderes privados o públicos, con matices diferenciadores ${ }^{48}$.

\footnotetext{
48 De tal forma se enfatiza y refuerza al mismo tiempo la garantía de los derechos sociales y en general del objeto de los derechos constituidos por aquellos bienes (por ej. afianzando así las posibilidades reales de cumplimiento de prestaciones obligatorias y universales, bajo los principios de indivisibilidad, interdependencia, de igualdad). Solo varían, en el caso de los bienes vitales, el tipo de obligaciones y vínculos impuestos a la producción y distribución de tales bienes (por ej. el agua, los fármacos salvavidas) y las prohibiciones y límites a su apropiación privada y a su devastación, como lo resalta Ferrajoli. Es decir varía el contenido del marco conceptual pero no el enfoque protectorio y garantista relacionado.
} 